\title{
Unraveling the activity of iron carbide clusters embedded in silica for thermocatalytic conversion of methane
}

\author{
Gopal K. Dixit, ${ }^{\dagger} \S$ Manish Kumar, ${ }^{\dagger, \S}$ Ankita Katiyar, ${ }^{\dagger}$ Antonius P. J. Jansen, ${ }^{\ddagger}$ \\ Alexander P. van Bavel, " Ravi Agrawal, ${ }^{\ddagger}$ Prathamesh M. Shenai, ${ }^{*} \ddagger$ and \\ Varadharajan Srinivasan ${ }^{* \dagger}$ \\ $\dagger$ Department of Chemistry, Indian Institute of Science Education and Research Bhopal, \\ Bhopal 462 066, India \\ $\ddagger$ Shell India Markets Pvt. Ltd., Bengaluru, Karnataka 562149, India \\ 9Shell Global Solutions International B. V. $1031 \mathrm{HW}$ Amsterdam, Netherlands \\ $\S$ Contributed equally to this work
}

E-mail: Prathamesh.Shenai@shell.com; vardha@iiserb.ac.in 


\begin{abstract}
Isolated Fe-sites on silica substrate have recently been reported for direct and non-oxidative conversion of gaseous methane with high selectivity. The activated catalyst was proposed to be $\mathrm{FeC}_{2}$ cluster embedded in silica. Using a combination of density-functional theoretic methods and micro-kinetic modeling, we show that under the same reaction conditions (1223 K, $1 \mathrm{~atm}$ ) $\mathrm{FeC}_{2}$ sites convert to $\mathrm{FeC}_{3}$ and the latter is instead responsible for the observed activity. We investigate the detailed mechanism of conversion of methane to methyl radical and hydrogen on $\mathrm{FeC}_{3} @ \mathrm{SiO}_{2}$ under different conditions of methane partial pressure. We find that methyl radical evolution is the rate-determining step for the overall conversion. Our calculations also indicate that the conversion of embedded $\mathrm{FeC}_{3}$ to $\mathrm{FeC}_{4}$ competes with methyl radical evolution from the active catalyst. However, due to the higher stability of $\mathrm{FeC}_{3}$ sites, we anticipate that formation of higher carbides can be inhibited by controlling the hydrogen partial pressure.
\end{abstract}

\section{Introduction}

Ever growing demand of methane as a cleaner alternative to the traditional non-renewable energy sources, such as coal and oil, and as a feedstock material for other useful chemicals, ${ }^{1-3}$ such as olefins and aromatics has been constantly propelled over the decades, thanks to continuing discovery of its new potential reservoirs in the form of natural gas, shale gas and gas hydrates. Given the typically remote locations of such sources, transportation in the gas phase has serious drawbacks in terms of safety and economics. An established way to tackle this problem is by inducing a phase change to produce liquefied natural gas. However, an even more attractive route can be opened up if methane can be chemically converted into other high-density, high-value chemicals.

Methane conversion to other valuable materials is conventionally realized by an indirect route , ${ }^{4-6}$ involving formation of the intermediate syngas $\left(\mathrm{CO}+\mathrm{H}_{2}\right)$. The overall process, however, takes place through various energy intensive intermediate steps, leading to high operational cost. A potentially cheaper, eco-friendly, but currently challenging, alternative route is the direct conversion of methane ${ }^{7,8}$ to other hydrocarbons. The main bottleneck is its stability, with the energy required to break the first $\mathrm{C}-\mathrm{H}$ bond equal to almost $104 \mathrm{Kcal} / \mathrm{mol}$. The high activation energy of methane comes from its highly symmetrical geometry and non-polar nature, which makes it both poor electron acceptor and donor.
Nevertheless, owing to its huge potential, both theoretical as well as experimental efforts over the past few decades have aimed at designing new catalysts which can be used effectively to facilitate $\mathrm{CH}_{4}$ activation. ${ }^{9}$ In this regard, the catalysts based on noble materials like $\mathrm{Pt}, \mathrm{Ru}$, $\mathrm{Au}$, Ir and $\mathrm{Ag}$ have been shown to exhibit excellent activity as well as reasonable selectivity towards the formation of desired products . ${ }^{10-18}$ However, their high cost and susceptibility to deactivation, especially at higher temperatures, hinder their industrial scale utilization. Possibly due to these drawbacks, currently catalysts designed using cheap and easily available firstrow transition metals, ${ }^{19-21}$ such as $\mathrm{Fe}$ and $\mathrm{Cu}$, are gaining prominence.

Single atom catalysts (SACs), a relatively new class of catalysts, consist of well dispersed metal atoms or their small clusters with same or different material atoms are embedded in or adsorbed on different support materials. ${ }^{22}$ As shown in various studies, carefully chosen support materials can vitally modulate overall activity of the catalyst. ${ }^{23,24}$ In comparison to the traditional heterogeneous catalysts which contain different kinds of catalytic activity centers, SACs provide isolated, uniform and well characterized catalytic activity centers which lead to better activity and selectivity.

In a recent seminal work, Guo and coworkers ${ }^{25}$ have synthesized a new catalyst for methane activation, which exhibits very high selectivity towards ethylene and aromatic formation. The catalyst was formed by fusing quartz with ferrous meta-silicate at elevated 
temperature, followed by leaching with aqueous $\mathrm{HNO}_{3}$. The catalyst was shown to convert 48.1 $\%$ of methane without any formation of coke or $\mathrm{CO}_{2}$. Further, the catalyst was found to be very stable, able to work up to 60 hrs without any deactivation at $1293 \mathrm{~K}$. The catalyst was reported to contain isolated iron carbide $\left(\mathrm{FeC}_{2}\right)$ clusters embedded in silica matrix $\left(\mathrm{FeC}_{2} @ \mathrm{SiO}_{2}\right)$, in the activated form, which was argued to be critical towards suppression of coke formation.

Recently, a combined experimental and computational study, ${ }^{26}$ in which reactivity of various iron-carbide cluster anions $\left(\mathrm{FeC}_{y}^{-}\right)$towards methane was investigated in high temperature conditions $(300 \mathrm{~K}-700 \mathrm{~K})$, has revealed that $\mathrm{FeC}_{3}^{-}$cluster is much more active than $\mathrm{FeC}_{2}^{-}$. Based on these works, it is of interest to investigate stability as well as catalytic activity of different iron-carbide clusters embedded in $\mathrm{SiO}_{2}$ framework.

In the present study, we provide a detailed and systematic discussion of the $\mathrm{CH}_{4}$ decomposition pathways over the silica embedded $\mathrm{FeC}_{3}$ catalyst. The complete reaction proceeds through various elementary reaction steps, each one consisting of intermediates and transition states. We calculate the energy of different possible states along the reaction network and construct associated potential energy surfaces, which clearly illustrate the possibility of interconversions taking place during the reaction. Aided by microkinetic modeling, this analysis enables us to explore the activity of $\mathrm{FeC}_{2} @ \mathrm{SiO}_{2}$ and $\mathrm{FeC}_{3} @ \mathrm{SiO}_{2}$ towards the methane decomposition.

Our analysis also renders the formation of other higher analogues of iron-carbide clusters in the reaction conditions less likely, thus substantiating the absence of coke formation during the reactions. By re-examining the $\mathrm{C}$ $\mathrm{H}$ activation reactions on the previously reported $\mathrm{FeC}_{2} @ \mathrm{SiO}_{2}$ catalyst, we are also able to predict in situ formation of $\mathrm{FeC}_{3} @ \mathrm{SiO}_{2}$ from $\mathrm{FeC}_{2} @ \mathrm{SiO}_{2}$ through a favorable path that was not considered in the earlier study. ${ }^{25}$ Thus, the experimentally observed catalytic activity may not be exclusively due to $\mathrm{FeC}_{2} @ \mathrm{SiO}_{2}$ as previously claimed. Further, we compare the activities of the two systems and show that the sequential $\mathrm{C}-\mathrm{H}$ activation barriers of two methane molecules (where two $\mathrm{CH}_{4}$ molecules are used to ensure full catalytic cycle) are higher for $\mathrm{FeC}_{3} @ \mathrm{SiO}_{2}$ than $\mathrm{FeC}_{2} @ \mathrm{SiO}_{2}$ whereas methyl radical and hydrogen evolution processes are kinetically and thermodynamically more favourable in case of $\mathrm{FeC}_{3} @ \mathrm{SiO}_{2}$. In essence, this analysis underlines the importance of in situ formed $\mathrm{FeC}_{3} @ \mathrm{SiO}_{2}$ sites in the overall observed experimental activity of the iron carbide clusters towards methane conversion.

\section{Computational details}

In the present study, all calculations were performed using Vienna Ab Initio Simulation Package (VASP), ${ }^{27-30}$ with the generalized gradient approximation $(\mathrm{PBE})^{31}$ used to describe the exchange-correlation interactions. In the calculations, ionic cores were described by projector augmented wave (PAW) ${ }^{32,33}$ pseudopotentials and electron wave function was expanded using plane waves with an energy cutoff of $800 \mathrm{eV}$. Spin-polarized calculations were performed due to the presence of Fe atom in the system.

Similar to the previous study, ${ }^{25}$ an $\mathrm{O}$ terminated (001) surface of crystalline silica $(\beta$ tridymite phase, due to its stability in the given temperature range) was taken as support matrix and the catalyst surface $\left(\mathrm{FeC}_{3} @ \mathrm{SiO}_{2}\right.$ and $\mathrm{FeC}_{2} @ \mathrm{SiO}_{2}$ ) was constructed by substituting one of its surface $\mathrm{SiO}_{3}$ unit with $\mathrm{FeC}_{2}$ or $\mathrm{FeC}_{3}$ clusters, while saturating dangling bonds associated to surface $\mathrm{O}$ atoms with $\mathrm{H}$ atoms (see Fig. 1).

A three-layer slab of $\mathrm{SiO}_{2}$, periodically repeated in $\sqrt{3} \times \sqrt{3}$ supercell geometry with the vacuum region of $\geq 20 \AA$ between two successive slabs was used. The lattice parameters of the passivated slab were optimized. The optimized lattice parameters are in good agreement with experimental lattice parameters (see SI). To study the reaction on $\mathrm{FeC}_{x}$ cluster embedded silica surface, one bottom layer was kept fixed, whereas top two layers were allowed to relax. Geometry relaxation calculations were carried out by using conjugate-gradient algo- 
rithm. ${ }^{34}$ For geometry optimization and transition state search calculations, a $3 \times 3 \times 1$ $\Gamma$-centered Monkhorst-Pack $k$-point mesh was used to sample Brillouin zone.

Transition states (TSs) associated to different elementary reactions were obtained using Climbing Image Nudge Elastic Band (CINEB) ${ }^{35,36}$ and Dimer schemes. ${ }^{37}$ In NEB calculations, spring constant between two adjacent intermediate images was taken equal to $5.0 \mathrm{eV} / \AA$. A quasi-Newton algorithm, ${ }^{38}$ as provided with VTST tools, ${ }^{39}$ was used for optimization of NEB images. All the transition states (intermediates) were further verified via frequency calculations, which yield single (no) imaginary frequency. In reactions steps corresponding to evolution, TSs were estimated from enthalpy change of the reactions. The Hellmann-Feynman force threshold for optimization and transition state calculations were taken as $0.001 \mathrm{eV} / \AA$ and $0.01 \mathrm{eV} / \AA$, respectively. Additionally, energy convergence threshold were taken to be $10^{-8} \mathrm{eV}$ and $10^{-6} \mathrm{eV}$ for the two calculations, respectively. The total energy convergence with respect to various crucial parameters such as energy cutoff, $k$-point grid and vacuum size was affirmed before performing actual calculations. Graphics of all the structures, charge density isosurfaces were created using VESTA. ${ }^{40}$

The adsorption energy of methane molecule over the catalyst was calculated by using the definition $E_{a d s}=E_{\left(\mathrm{CH}_{4}-\mathrm{FeC}_{x} @ \mathrm{SiO}_{2}\right)}-E_{\mathrm{CH}_{4}}-$ $\left.E_{(\mathrm{FeC}} @ \mathrm{SiO}_{2}\right)$, where $E_{\left(\mathrm{CH}_{4}-\mathrm{FeC}_{x} @ \mathrm{SiO}_{2}\right)}, \quad E_{\mathrm{CH}_{4}}$ and $E_{\left(\mathrm{FeC}_{x} @ \mathrm{SiO}_{2}\right)}$ are the total internal energies of absorbed system, isolated methane molecule, and the catalyst, respectively. In order to analyze charge transfer during elementary reaction steps Bader charges and electron density differences were calculated. The electron density difference was calculated as $\Delta \rho=\rho_{\mathrm{AB}}-\rho_{\mathrm{A}}-\rho_{\mathrm{B}}$, where $\rho_{\mathrm{AB}}\left(\rho_{\mathrm{A}} / \rho_{\mathrm{B}}\right)$ is the electron density of structure $\mathrm{AB}(\mathrm{A} / \mathrm{B})$, and $\mathrm{AB}$ is the combination of $\mathrm{A}$ and $\mathrm{B}$, formed either by adsorption or embedding of one into other.

Energy values of various intermediates and TSs, as reported in the results and discussion section, are Gibbs free energies calculated with respect to a reference state consisting of the catalyst (IS) and two isolated methane molecules. Additionally, the absolute free energy of a given species is calculated using definition $G=E+Z P E-T S$, where $E, Z P E$, and $S$ are associated internal energy, zero point energy, and entropy, respectively, and $\mathrm{T}$ is the reaction temperature. The entropies of gas-phase species were taken from literature. ${ }^{41}$ However, in the subsection describing methane adsorption, energies $\mathrm{E}_{\mathrm{ads}}$ are reported in terms of internal energies to make an explicit comparison with earlier studies.
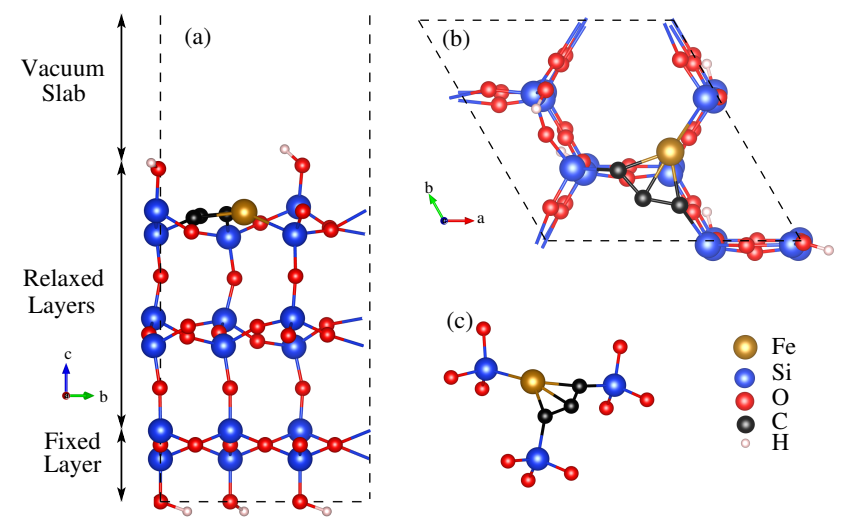

Figure 1: Ball and stick model of (a) Side view, (b) Top view, and (c) Active site of the initial geometry of the the catalyst

To better interpret the energetics of the various reactions we modeled the kinetics of the system. We calculated the rate constants of all the reaction steps, except the adsorption of methane, using the following expression:

$$
k=\frac{k_{\mathrm{B}} T}{h} \exp \left[-\frac{\Delta G}{k_{\mathrm{B}} T}\right] .
$$

The rate constant of the methane adsorption depends on the methane partial pressure at the adsorption site and the size of the site, ${ }^{42}$ which is difficult to know under actual reaction conditions. We, therefore, determined the kinetics as a function of the rate constant of methane adsorption and varied that over many orders of magnitude. We used the functions for solving sets of stiff ordinary differential equations from Matlab for the rate equations. ${ }^{43}$ By looking at large times, all the steady-state properties, such as relative concentration of all struc- 
tures and the rates of all reactions, could be determined. We also did a simple sensitivity analysis by reducing the rate constants of the forward and reverse reactions for each reversible processes. Irreversible processes were treated as a reversible process with a reverse reaction rate constant equal to zero. (Note that changing the rate constant of only a forward or only a reverse reaction would effectively mean a violation of the conservation of energy.) By looking at how this changes the kinetics we could determine the rate-determining reactions.

\section{Results and discussion}

The overall reaction procedure described here consists of successive activation of two methane molecules, where each activation takes place through the following three reaction steps: (1) methane adsorption on the catalyst surface, (2) transfer of one or more $\mathrm{H}$ atoms from methane to the $\mathrm{C}$ atoms of $\mathrm{FeC}_{3}$ consequent to $\mathrm{C}-\mathrm{H}$ bond breaking, and (3) methyl radical evolution (i.e. release of methyl radical from the surface into gas-phase and assuming $\mathrm{C}_{2}$ formation via methyl radical evolution in gas-phase). An additional step that completes the reaction and regenerates initial catalyst surface, is the eventual $\mathrm{H}_{2}$ evolution. These reaction steps, with the various alternative pathways contained therein, are presented in this section, subsequent to describing structure and stability of the active site. In addition to this, some important states, such as adsorbed states of the two methane molecules and the transition states (TSs) involved in the $\mathrm{C}-\mathrm{H}$ bond breaking, are described explicitly and compared with the available literature in the present section. For brevity, adsorption of the two methane molecules and the geometries of these transition states are described together in separate subsections.

In the description, initial state, intermediates, and TSs are denoted by symbols IS, I and FS, and TS, respectively, with each symbol suffixed and prefixed (as superscript) by different numbers representing their order in the overall reaction and associated spin states, respectively. TSs estimated from enthalpy change calculations are represented by an additional asterisk $\left(^{*}\right)$ symbol. To distinguish between the pathways initiated from $\mathrm{FeC}_{2} @ \mathrm{SiO}_{2}$ and $\mathrm{FeC}_{3} @ \mathrm{SiO}_{2}$, symbols for the initial state, intermediates, and TSs are prefixed by $r$ in the former case. The numbers in red superscript represent the spin multiplicity of corresponding states.

All the significant elementary reaction steps associated to methane activation on $\mathrm{FeC}_{3} @ \mathrm{SiO}_{2}$ are listed in Table 1, while the associated reaction pathways and energy surfaces are provided in Figs. 3 and 4. Note that same color code is used in the two Figs. 3 and 4, and in Table 1 for representing various reaction steps. Similar information describing activity of the catalyst $\mathrm{FeC}_{2} @ \mathrm{SiO}_{2}$ is given in the Figs. 6, 7 and 8 and Table S1 in supplementary information.

\section{Structure and stability of active site}

As reported previously, ${ }^{25}$ lattice confined single Fe sites embedded in $\mathrm{SiO}_{2}$ matrix can be converted into corresponding $\mathrm{FeC}_{2}$ sites on treatment with $\mathrm{CH}_{4}$ at elevated temperature. In our study we find that, under the same reaction conditions $(1223 \mathrm{~K})$, conversion of $\mathrm{FeC}_{2}$ site into corresponding $\mathrm{FeC}_{3}$ site is also thermodynamically as well as kinetically favorable. Detailed discussion for in situ conversion of $\mathrm{FeC}_{2}$ sites into $\mathrm{FeC}_{3}$ sites at $\mathrm{SiO}_{2}$ is provided later in this section.

Geometry of an active site of the catalyst containing of $\mathrm{FeC}_{3}$ embedded in $\mathrm{SiO}_{2}$ matrix $\left(\mathrm{FeC}_{3} @ \mathrm{SiO}_{2}\right)$ is shown in Fig 1. During $\mathrm{FeC}_{2}$ to $\mathrm{FeC}_{3}$ conversion, a new $\mathrm{C}$ atom is inserted between the two $\mathrm{C}$ atoms of $\mathrm{FeC}_{2}$ resulting in a fan-like geometry. Bond distances of $\mathrm{Fe}$ with two terminal $\mathrm{C}$ atoms $\left(\mathrm{Fe}-\mathrm{C}_{\mathrm{t} 1}, \mathrm{Fe}-\mathrm{C}_{\mathrm{t} 2}\right)$, and one middle $\mathrm{C}$ atom $\left(\mathrm{C}_{\mathrm{c}}\right)$ are $1.925,1.923$ and 1.922 $\AA$, respectively. We find that in $\mathrm{FeC}_{3} @ \mathrm{SiO}_{2}$, net excess electronic charge on the $\mathrm{FeC}_{3}$ moiety is -1.19 e making it structurally and electronically similar to the gas phase $\mathrm{FeC}_{3}^{-}$species. ${ }^{26}$ The charge density difference plot shows (see Fig 2) that this excess charge is transferred from neighboring $\mathrm{Si}$ atoms of the support to terminal $\mathrm{C}$ atoms. The $\mathrm{FeC}_{3} @ \mathrm{SiO}_{2}$ catalyst is in quartet 


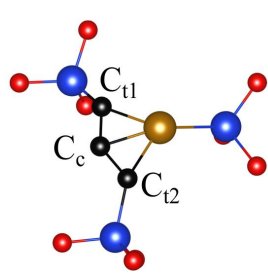

(a)

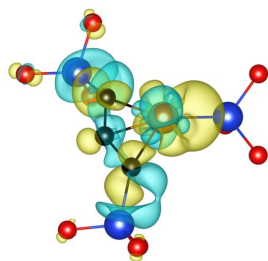

(d)

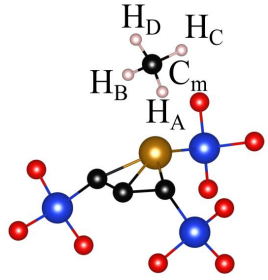

(b)

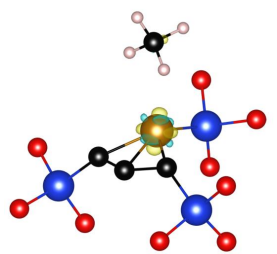

(e)

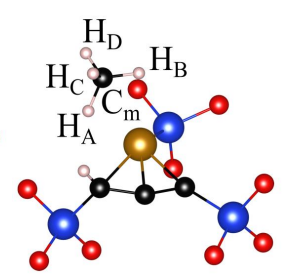

(c)

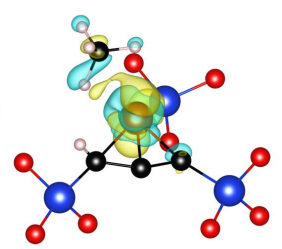

(f)
Figure 2: Active-site geometries and resulting charge density differences during embedding of $\mathrm{FeC}_{3}$ into $\mathrm{SiO}_{2}$ support [ ${ }^{4} \mathrm{IS}$, (a) and (d)], during adsorption of first $\left[{ }^{4} \mathrm{I} 1,(\mathrm{~b})\right.$ and (e)] and second methane molecule $\left[{ }^{3} \mathrm{I} 2\right.$, (c) and (f)] on the catalyst surface $\mathrm{FeC}_{3} @ \mathrm{SiO}_{2}$, respectively. Yellow (blue) color represents region of charge accumulation (depletion). Isosurface value used is $0.005 \mathrm{a}_{0}^{-3}$ where $\mathrm{a}_{0}$ is Bohr radius. The solid spheres represent the atoms: $\mathrm{Si}$ (blue), C (black), Fe (golden), O (red) and $\mathrm{H}$ (white).

state with all its unpaired electrons primarily located on the Fe atom.

\section{$\mathrm{CH}_{4}$ Adsorption}

Overall reaction starts with the adsorption of methane molecule on the active site of catalyst. During adsorption, methane binds through its $\mathrm{C}$ atom $\left(\mathrm{C}_{\mathrm{m}}\right)$ to $\mathrm{Fe}$ atom of the catalyst with two of its $\mathrm{H}$ atoms $\left(\mathrm{H}_{\mathrm{A}}\right.$ and $\left.\mathrm{H}_{\mathrm{B}}\right)$ pointing towards the catalyst surface. $\mathrm{Fe}-\mathrm{C}_{\mathrm{m}}, \mathrm{Fe}-\mathrm{H}_{\mathrm{A}}$ and $\mathrm{Fe}-\mathrm{H}_{\mathrm{B}}$ bond distances are equal to $2.79 \AA, 2.36$ $\AA$ and $2.49 \AA$, respectively. As a result of adsorption, intramolecular bond distances between $\mathrm{C}$ and $\mathrm{H}$ atoms slightly elongate from $1.09 \AA$ to $1.10 \AA$. The $\mathrm{H}-\mathrm{C}-\mathrm{H}$ bond angle directed towards the surface $\left(\mathrm{H}_{\mathrm{A}}-\mathrm{C}_{\mathrm{m}}-\mathrm{H}_{\mathrm{B}}\right)$ and towards vacuum $\left(\mathrm{H}_{\mathrm{C}^{-}} \mathrm{C}_{\mathrm{m}}-\mathrm{H}_{\mathrm{D}}\right)$ are $112.35^{\circ}$ and $110.94^{\circ}$, respectively. The adsorption energy of a methane molecule is $-0.09 \mathrm{eV}$. During adsorp- tion, a small amount of electronic charge (0.009 $e)$ is transferred from the $\mathrm{CH}_{4}$ to surface.

After the second $\mathrm{CH}_{4}$ adsorption, $\mathrm{C}_{\mathrm{m}}-\mathrm{Fe}, \mathrm{Fe}-$ $\mathrm{H}_{\mathrm{A}}$ and $\mathrm{Fe}-\mathrm{H}_{\mathrm{B}}$ bond distances are $2.32 \AA, 1.85$ $\AA, 2.15 \AA$, while the $\mathrm{C}_{\mathrm{m}}-\mathrm{H}$ bonds closest to the surface are elongated to $1.13 \AA\left(\mathrm{C}_{\mathrm{m}}-\mathrm{H}_{\mathrm{A}}\right)$ and $1.11 \AA\left(\mathrm{C}_{\mathrm{m}}-\mathrm{H}_{\mathrm{B}}\right)$, respectively. In this case, electron density builds up in the region between $\mathrm{C}$ and $\mathrm{Fe}$ atoms. This electron density redistribution during adsorption leads to the change of multiplicity from quintet to triplet. However, overall charge transfer from $\mathrm{CH}_{4}$ to the catalyst is $0.03 e$ and adsorption energy is -0.07 $\mathrm{eV}$, which is similar to corresponding values in first methane adsorption. Bader charge analysis of both adsorption processes indicates that the $\mathrm{CH}_{4}$ molecule and embedded $\mathrm{FeC}_{3}$ moiety lose electron charges of $0.009 e$ and $0.022 e$ during first adsorption, and $0.033 e$ and $0.03 e$ during second adsorption to $\mathrm{SiO}_{2}$ substrate. This is also confirmed by the gain of corresponding charges by silica support during first and second methane adsorption. Therefore, it can be said that the silica support plays electrophilic role in adsorption processes.

In general, on transition metal surfaces, sticking properties of methane are found to be very low. Therefore, particularly in high temperature reaction conditions, methane activation is assumed to take place through dissociative adsorption, ${ }^{44}$ in which colliding methane molecules with kinetic energy greater than the associated reaction barrier undergo a direct $\mathrm{C}$ $\mathrm{H}$ bond rupture without any intermediate reorientation.

At this point, it is also important to mention that in some previous studies where methane adsorption takes place directly over the $\mathrm{Fe}^{+}$ containing active sites, adsorption energies have been found to be larger ${ }^{21,45,46}$ than those computed here. However, unlike these studies, Fe atom does not behave like an electrophile in the present context, which is evident from the almost equal charge densities on the $\mathrm{Fe}$ atom before and after both first $(-0.70 e$ and $-0.75 e)$ and second (-0.69 $e$ and $-0.63 e)$ methane adsorption. Furthermore, in the present scenario, the small adsorption energy observed can also be attributed to geometrical frustration arising 


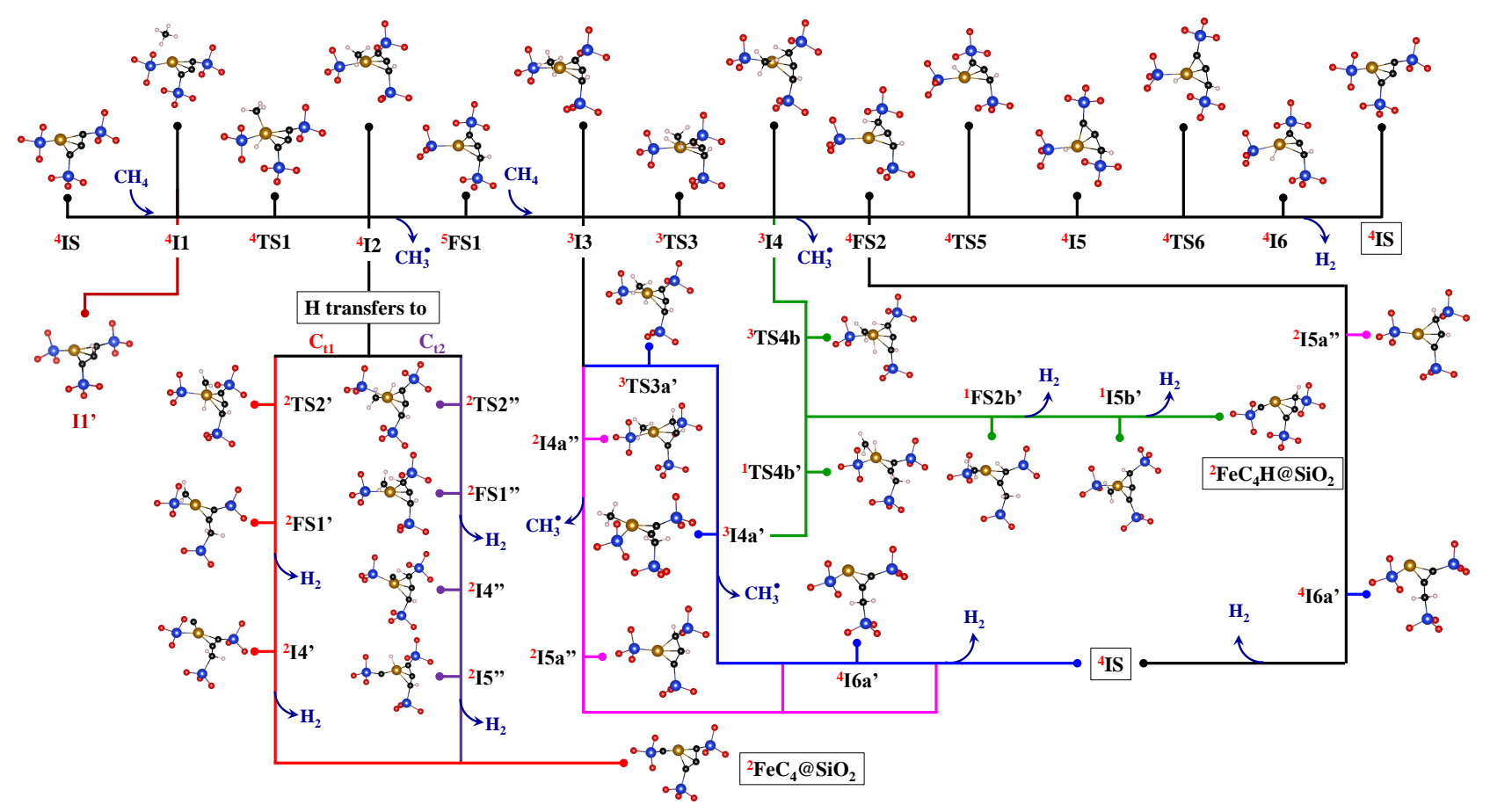

Figure 3: Elementary reaction pathways which can contribute significantly in the overall reaction. Discontinued reaction branch $\mathrm{I} 1 \rightarrow \mathrm{I}^{\prime}$ can be ruled out on the basis of energy considerations. TSs of some evolution reactions, which are estimated from associated enthalpy change, are not shown in the figure. The numbers in red superscript are the spin multiplicity of corresponding states.

due to embedding of $\mathrm{FeC}_{3}$ in silica support.

\section{First methane activation}

As a result of dissociative adsorption, gas phase methane molecule $\left({ }^{4} \mathrm{IS}\right)$ transfers its $\mathrm{H}$ atom to one of the two terminal $\mathrm{C}$ atoms $\left(\mathrm{C}_{\mathrm{t} 1}\right.$ or $\left.\mathrm{C}_{\mathrm{t} 2}\right)$ of embedded $\mathrm{FeC}_{3}$ moiety. However, transfer of $\mathrm{H}$ atom to $\mathrm{C}_{\mathrm{t} 1}$ is thermodynamically more favourable than to $\mathrm{C}_{\mathrm{t} 2}$ by $0.11 \mathrm{eV}$. Reaction energy and transition barrier $\left({ }^{4} \mathrm{TS} 1\right)$ of this $\mathrm{H}-$ transfer step with respect to ${ }^{4} \mathrm{IS}$ state, are estimated as $2.49 \mathrm{eV}$ and $3.54 \mathrm{eV}$, respectively. The alternative possibility involving transfer of methane $\mathrm{H}$ atom to middle $\mathrm{C}$ atom $\left(\mathrm{C}_{\mathrm{c}}\right)$ of $\mathrm{FeC}_{3}$ led to an unstable intermediate geometry and, hence, was not considered further.

After H-transfer step has taken place, $\mathrm{CH}_{3} \bullet$ evolves in an exergonic reaction step $\left({ }^{4} \mathrm{I} 2 \rightarrow{ }^{5} \mathrm{FS} 1,-1.37 \mathrm{eV}\right)$, with an associated reaction barrier equal to $1.96 \mathrm{eV}$. Methyl radical evolution at the end of first methane activation reaction step makes the Fe site available for adsorption of another methane molecule.
An alternative pathway to the $\mathrm{CH}_{3} \bullet$ evolution step involves transfer of another $\mathrm{H}$ atom from the attached methyl group in ${ }^{4} \mathrm{I} 2$ to one of the three $\mathrm{C}$-atoms of $\mathrm{FeC}_{3}$, leading to an intermediate, having a $\mathrm{CH}_{2}$ group bonded to $\mathrm{Fe}$ and two $\mathrm{H}$ atoms bonded to either same or different $\mathrm{C}$ atoms of $\mathrm{FeC}_{3} .{ }^{2} \mathrm{FS}^{\prime}$ is one such intermediate, in which both transferred $\mathrm{H}$-atoms are attached to the same terminal $\mathrm{C}$ atom. Other possible alternatives are those in which the two $\mathrm{H}$ atoms are transferred one by one to each of the two terminal $\mathrm{C}$ atoms of $\mathrm{FeC}_{3}\left({ }^{2} \mathrm{FS} 1 "\right)$ or to one terminal and one middle (FS1"') $\mathrm{C}$ atoms. Intermediate $\mathrm{FS}^{\prime \prime \prime}$ is not shown in the Fig 3.

Reaction energies for the formation of intermediates ${ }^{2} \mathrm{FS}^{\prime}$ and ${ }^{2} \mathrm{FS} 1^{\prime \prime}$ from ${ }^{4} \mathrm{I} 2$ state are estimated as $0.29 \mathrm{eV}$ and $0.69 \mathrm{eV}$, respectively. These intermediates are important as they can act as precursors to the formation of $\mathrm{FeC}_{4}$ from $\mathrm{FeC}_{3}$ through two successive $\mathrm{H}_{2}$ evolution steps, one from $\mathrm{CH}_{2}$ group attached to $\mathrm{Fe}$ atom and one from the $\mathrm{C}$ atoms of $\mathrm{FeC}_{3}$. As is evident from the estimated reaction energies (see Fig. 4(b)), these reaction steps 
are themselves thermodynamically unfavorable with respect to the competitive reaction, i.e. methyl radical evolution, under the given reaction conditions, thus inhibiting formation of $\mathrm{FeC}_{4} @ \mathrm{SiO}_{2}$. However, energy barriers for ${ }^{2} \mathrm{FS}^{\prime}$ $(0.89 \mathrm{eV})$ and ${ }^{2} \mathrm{FS}^{\prime \prime}(1.38 \mathrm{eV})$ formation are smaller than the $\mathrm{CH}_{3} \bullet$ evolution barrier to form ${ }^{5} \mathrm{FS} 1$, suggesting that the ${ }^{2} \mathrm{FeC}_{4} @ \mathrm{SiO}_{2}$ formation through these intermediates is kinetically favourable over $\mathrm{CH}_{3} \bullet$ evolution. If the formation of higher carbides by dehydrogenation of methane continues then coke formation is expected at the silica surface.

\section{Second methane activation}

Second methane activation takes place in the same manner as the first one, i.e. during reaction, gaseous methane molecule transfers its $\mathrm{H}$ atom to one of the $\mathrm{C}$ atoms of $\mathrm{FeC}_{3}$ moiety through a weakly adsorbed intermediate state. Depending on which of the $\mathrm{C}$ atoms $-\mathrm{C}_{\mathrm{t} 1}$, $\mathrm{C}_{\mathrm{t} 2}$ and $\mathrm{C}_{\mathrm{c}}$ - receives the $\mathrm{H}$, this yields one of the three possible intermediates, ${ }^{3} \mathrm{I} 4,{ }^{3} \mathrm{I} 4 \mathrm{a}^{\prime}$ and ${ }^{3} \mathrm{I} 4 \mathrm{a}^{\prime \prime}$, respectively.

Reaction energies and transition barriers for the reaction ${ }^{5} \mathrm{FS} 1 \rightarrow{ }^{3} \mathrm{I} 4$ are estimated to be 3.32 $\mathrm{eV}$ and $3.60 \mathrm{eV}$, while those for ${ }^{5} \mathrm{FS} 1 \rightarrow{ }^{3} \mathrm{I} 4 \mathrm{a}^{\prime}$ are $3.01 \mathrm{eV}$ and $3.88 \mathrm{eV}$. It is evident that, under the given reaction conditions, both these elementary reaction steps contribute significantly to the overall reaction. However, the third possibility of H-transfer, ${ }^{5} \mathrm{FS} 1 \rightarrow{ }^{3} \mathrm{I} 4 \mathrm{a}^{\prime \prime}$, has reaction energy of $3.79 \mathrm{eV}$, almost equal to the transition barriers of its alternatives, making it less likely to occur (see $4(\mathrm{~d})$ ).

Subsequent to the H-transfer step, second methyl radical evolution from the catalyst surface takes place. Similar to the first methyl radical evolution, the three possible evolution steps $\left({ }^{3} \mathrm{I} 4 \rightarrow{ }^{4} \mathrm{FS} 2,{ }^{3} \mathrm{I}_{4} \mathrm{a}^{\prime} \rightarrow{ }^{4} \mathrm{I}_{6 \mathrm{a}},{ }^{3} \mathrm{I}_{4} \mathrm{a}^{\prime \prime} \rightarrow\right.$ $\left.{ }^{4} \mathrm{I} 5 \mathrm{a}^{\prime \prime}\right)$ are also exergonic with reaction energies of $-1.52 \mathrm{eV},-1.44 \mathrm{eV}$ and $-1.53 \mathrm{eV}$, respectively. The associated transition barriers are $1.81 \mathrm{eV}, 1.89 \mathrm{eV}$, and $1.82 \mathrm{eV}$, respectively. Alternatively, a second $\mathrm{H}$-atom from the methyl group could be transferred to one of the three $\mathrm{C}$ atoms of $\mathrm{FeC}_{3}$. The rupture of $\mathrm{C}-\mathrm{H}$ bonds of $\mathrm{CH}_{3} \bullet$ in ${ }^{3} \mathrm{I} 4$ and ${ }^{3} \mathrm{I}_{4} \mathrm{a}^{\prime}$ involve activation bar- riers of $1.80 \mathrm{eV}$ and $1.20 \mathrm{eV}$, respectively leading to the formation of ${ }^{1} \mathrm{FS} 2 \mathrm{~b}^{\prime}$ which eventually forms ${ }^{2} \mathrm{FeC}_{4} \mathrm{H} @ \mathrm{SiO}_{2}$ after two successive $\mathrm{H}_{2}$ evolutions (see Fig. 4(c)).

\section{Transition state geometries associ- ated to $\mathrm{C}-\mathrm{H}$ activation}

As shown in the previous studies, ${ }^{47}$ in transition metal catalyzed methane activation reactions, it is the deformation of methane during adsorption which paves path for eventual $\mathrm{C}-\mathrm{H}$ bond scission through transition state. In the present study, the transition states TS1, TS3 and TS3a' are associated to this class of transitions states where $\mathrm{C}-\mathrm{H}$ bond scission takes place as a result of $\mathrm{CH}_{4}$ adsorption. Other transition states, such as TS2', TS2" and TS3b, TS3b' are associated with $\mathrm{C}-\mathrm{H}$ bond scission of methyl group bonded to Fe.

The geometries of the different TSs are shown in Fig. 2 and important structural parameters characterising these are listed in Table 2. In congruence with earlier studies, ${ }^{48}$ all three TSs can be conveniently characterized as late TSs, given their structural similarity to the corresponding final rather than initial states. This becomes evident when considering (a) well elongated $\mathrm{C}-\mathrm{H}_{\mathrm{A}}$ bond-distances as compared to those in methane molecule and, (b) short Fe- $\mathrm{C}_{\mathrm{m}}$ and $\mathrm{Fe}-\mathrm{H}_{\mathrm{A}}$ bond distances, comparable to those in optimized geometries having direct $\mathrm{Fe}-\mathrm{CH}_{3}$ and $\mathrm{Fe}-\mathrm{H}$ bonds, in the TS structures. Another characteristic feature that is ubiquitous in the computed TSs is that both the reacting $\mathrm{H}$ atom $\left(\mathrm{H}_{\mathrm{A}}\right)$ and $\mathrm{CH}_{3}$ are attached to the $\mathrm{Fe}$ atom.

\section{$\mathrm{H}_{2}$ evolution and catalyst regener- ation}

Major intermediates ${ }^{4} \mathrm{FS} 2$ and ${ }^{4} \mathrm{I} 6 \mathrm{a}$ ', formed as a consequence of $\mathrm{H}$-transfer followed by $\mathrm{CH}_{3} \bullet$ evolution through two different pathways, undergo $\mathrm{H}_{2}$ evolution reactions that eventually lead to the regeneration of initial catalyst.

$\mathrm{H}_{2}$ evolution from ${ }^{4} \mathrm{FS} 2$ takes place in three consecutive intermediate steps. In the first step $\left({ }^{4} \mathrm{FS} 2 \rightarrow{ }^{4} \mathrm{I} 5\right)$, one of the two $\mathrm{H}$ atoms attached to the terminal $\mathrm{C}$ atoms of $\mathrm{FeC}_{3}$ moves 
Table 1: Various elementary reaction steps with associated free/internal energy barriers $\left(\mathrm{G}_{\mathrm{a}}(1223 K) / \mathrm{E}_{\mathrm{a}}\right)$ and reaction free/internal energies $(\Delta \mathrm{G}(1223 \mathrm{~K}) / \Delta \mathrm{E})$. Those reaction barriers which either do not exist or have not been calculated (in insignificant reaction pathways), or have been estimated by enthalpy of associated reactions (evolution reactions) are shown by entries ' - ', $\mathrm{NA}$, and $\mathrm{G}_{\mathrm{a}}{ }^{*}$, respectively.

\begin{tabular}{|c|c|c|c|c|c|c|}
\hline Sr. No. & Elementary step & $\mathrm{E}_{\mathrm{a}}(\mathrm{eV})$ & $\Delta \mathrm{E}(\mathrm{eV})$ & $\mathrm{G}_{\mathrm{a}}(\mathrm{eV})$ & $\Delta \mathrm{G}(\mathrm{eV})$ & Remarks \\
\hline 1 & ${ }^{4} \mathrm{IS}+2 \mathrm{CH}_{4} \rightarrow{ }^{4} \mathrm{I} 1+\mathrm{CH}_{4}$ & - & -0.09 & - & 3.46 & 1st $\mathrm{CH}_{4}$ adsorption \\
\hline 2 & ${ }^{4} \mathrm{I} 1+\mathrm{CH}_{4} \rightarrow{ }^{4} \mathrm{I} 2+\mathrm{CH}_{4}$ & 0.23 & -1.01 & 0.08 & -0.96 & $\begin{array}{l}\text { H-transfer from } \mathrm{CH}_{4} \\
\text { to } \mathrm{FeC}_{3} \mathrm{C}\left(\mathrm{C}_{t 1}\right) \text { atom }\end{array}$ \\
\hline $3 \mathrm{a}$ & ${ }^{4} \mathrm{I} 2+\mathrm{CH}_{4} \rightarrow{ }^{5} \mathrm{FS} 1+\mathrm{CH}_{4}+\mathrm{CH}_{3} \bullet$ & - & 2.31 & $1.96^{*}$ & -1.37 & $\mathrm{CH}_{3} \bullet$ evolution \\
\hline $4 a$ & ${ }^{5} \mathrm{FS} 1+\mathrm{CH}_{3} \bullet+\mathrm{CH}_{4} \rightarrow{ }^{3} \mathrm{I} 3+\mathrm{CH}_{3} \bullet$ & - & -0.07 & - & 3.52 & second $\mathrm{CH}_{4}$ adsorption \\
\hline $5 \mathrm{a}$ & ${ }^{3} \mathrm{I} 3+\mathrm{CH}_{3} \bullet \rightarrow{ }^{3} \mathrm{I} 4+\mathrm{CH}_{3} \bullet$ & 0.24 & -0.19 & 0.09 & -0.20 & $\begin{array}{l}\text { H-transfer from } \mathrm{CH}_{4} \\
\text { to } \mathrm{FeC}_{3} \mathrm{C}\left(\mathrm{C}_{t 2}\right) \text { atom }\end{array}$ \\
\hline $6 \mathrm{a}$ & ${ }^{3} \mathrm{I} 4+\mathrm{CH}_{3} \bullet \rightarrow{ }^{4} \mathrm{FS} 2+2 \mathrm{CH}_{3} \bullet$ & - & 2.17 & $1.81^{*}$ & -1.52 & $\begin{array}{l}\text { Second } \mathrm{CH}_{3} \bullet \text { evolu- } \\
\text { tion }\end{array}$ \\
\hline $7 \mathrm{a}$ & ${ }^{4} \mathrm{FS} 2+2 \mathrm{CH}_{3} \bullet \rightarrow{ }^{4} \mathrm{I}+2 \mathrm{CH}_{3} \bullet$ & 0.16 & 0.09 & 0.003 & 0.08 & $\begin{array}{l}\mathrm{H} \text {-transfer from } \mathrm{C}_{t 2} \text { to } \\
\mathrm{Fe}\end{array}$ \\
\hline $8 \mathrm{a}$ & ${ }^{4} \mathrm{I} 5+2 \mathrm{CH}_{3} \bullet \rightarrow{ }^{4} \mathrm{I}_{6}+2 \mathrm{CH}_{3} \bullet$ & 0.04 & -0.07 & -0.10 & -0.09 & H-reorientation on Fe \\
\hline $9 \mathrm{a}$ & ${ }^{4} \mathrm{I} 6+2 \mathrm{CH}_{3} \bullet \rightarrow{ }^{4} \mathrm{IS}+\mathrm{H}_{2}+2 \mathrm{CH}_{3} \bullet$ & - & 1.82 & $1.48^{*}$ & -0.70 & $\mathrm{H}_{2}$ evolution \\
\hline $3 \mathrm{~b}$ & ${ }^{4} \mathrm{I} 2+\mathrm{CH}_{4} \rightarrow{ }^{2} \mathrm{FSI}^{\prime}+\mathrm{CH}_{4}$ & 1.07 & 0.26 & 0.89 & 0.29 & $\begin{array}{l}\text { Transfer of } 2 \text { nd } \mathrm{H} \text { of } \\
\mathrm{CH}_{4} \text { to }\left(\mathrm{C}_{t 1}\right) \text { of } \mathrm{FeC}_{3}\end{array}$ \\
\hline $4 b$ & ${ }^{2} \mathrm{FSI}^{\prime}+\mathrm{CH}_{4} \rightarrow{ }^{2} \mathrm{I}^{\prime}+\mathrm{H}_{2}+\mathrm{CH}_{4}$ & - & 2.40 & 2.03 & -0.15 & $\mathrm{H}_{2}$ evolution \\
\hline $5 \mathrm{~b}$ & $\begin{array}{l}{ }^{2} \mathrm{I}^{\prime}+\mathrm{H}_{2}+\mathrm{CH}_{4} \rightarrow{ }^{2} \mathrm{FeC}_{4} @ \mathrm{SiO}_{2} \\
+2 \mathrm{H}_{2}+\mathrm{CH}_{4}\end{array}$ & - & 1.22 & 0.86 & -1.32 & $\mathrm{H}_{2}$ evolution \\
\hline $3 \mathrm{c}$ & ${ }^{4} \mathrm{I} 2+\mathrm{CH}_{4} \rightarrow{ }^{2} \mathrm{FS}^{\prime \prime}+\mathrm{CH}_{4}$ & 1.53 & 0.70 & 1.38 & 0.69 & $\begin{array}{l}\text { Transfer of } 2 \mathrm{nd} \mathrm{H} \text { of } \\
\mathrm{CH}_{4} \text { to }\left(\mathrm{C}_{t 2}\right) \text { of } \mathrm{FeC}_{3}\end{array}$ \\
\hline $4 c$ & ${ }^{4} \mathrm{FS}^{\prime \prime}+\mathrm{CH}_{4} \rightarrow{ }^{2} \mathrm{I}^{\prime \prime}+\mathrm{H}_{2}+\mathrm{CH}_{4}$ & - & 1.61 & 1.26 & -0.93 & $\mathrm{H}_{2}$ evolution \\
\hline $5 c$ & ${ }^{2} \mathrm{I}_{4}^{\prime \prime}+\mathrm{H}_{2}+\mathrm{CH}_{4} \rightarrow{ }^{2} \mathrm{I}^{\prime \prime}+\mathrm{H}_{2}+\mathrm{CH}_{4}$ & NA & -0.17 & NA & -0.18 & H-reorientation on $\mathrm{Fe}$ \\
\hline $6 c$ & $\begin{array}{l}{ }^{2} \mathrm{I}^{\prime \prime}+\mathrm{H}_{2}+\mathrm{CH}_{4} \rightarrow{ }^{2} \mathrm{FeC}_{4} @ \mathrm{SiO}_{2} \\
+2 \mathrm{H}_{2}+\mathrm{CH}_{4}\end{array}$ & - & 1.74 & 1.42 & -0.77 & $\mathrm{H}_{2}$ evolution \\
\hline $5 \mathrm{~d}$ & ${ }^{3} \mathrm{I} 3+\mathrm{CH}_{3} \bullet \rightarrow{ }^{3} \mathrm{I}_{4} \mathrm{a}^{\prime}+\mathrm{CH}_{3} \bullet$ & 0.54 & -0.52 & 0.37 & -0.51 & $\begin{array}{l}\text { H-transfer from } \mathrm{CH}_{4} \\
\text { to } \mathrm{FeC}_{3} \mathrm{C}\left(\mathrm{C}_{t 1}\right) \text { atom }\end{array}$ \\
\hline $6 \mathrm{~d}$ & ${ }^{3} \mathrm{I}_{4} \mathrm{a}^{\prime}+\mathrm{CH}_{3} \bullet \rightarrow{ }^{4} \mathrm{I}_{6 \mathrm{a}^{\prime}+2 \mathrm{CH}_{3} \bullet}$ & - & 2.23 & $1.89^{*}$ & -1.44 & $\mathrm{CH}_{3} \bullet$ evolution \\
\hline $7 \mathrm{~d}$ & ${ }^{4} \mathrm{I} \mathrm{a}^{\prime}+2 \mathrm{CH}_{3} \bullet \rightarrow{ }^{4} \mathrm{IS}+\mathrm{H}_{2}+2 \mathrm{CH}_{3} \bullet$ & - & 2.11 & $1.69^{*}$ & -0.49 & $\mathrm{H}_{2}$ evolution \\
\hline $5 \mathrm{e}$ & ${ }^{3} \mathrm{I} 3+\mathrm{CH}_{3} \bullet \rightarrow{ }^{3} 14 \mathrm{a}^{\prime \prime}+\mathrm{CH}_{3} \bullet$ & NA & 0.29 & NA & 0.27 & $\begin{array}{l}\text { H-transfer from } \mathrm{CH}_{4} \\
\text { to } \mathrm{FeC}_{3} \mathrm{C}\left(\mathrm{C}_{\mathrm{c}}\right) \text { atom }\end{array}$ \\
\hline $6 e$ & ${ }^{3} \mathrm{I}_{4} \mathrm{a}^{\prime \prime}+\mathrm{CH}_{3} \bullet \rightarrow{ }^{2} \mathrm{I}^{2} \mathrm{a}^{\prime \prime}+2 \mathrm{CH}_{3} \bullet$ & - & 2.15 & $1.82^{*}$ & -1.53 & $\mathrm{CH}_{3} \bullet$ evolution \\
\hline $7 \mathrm{e}$ & ${ }^{2} \mathrm{I}_{5} \mathrm{a}^{\prime \prime}+2 \mathrm{CH}_{3} \bullet \rightarrow{ }^{4} \mathrm{IS}+\mathrm{H}_{2}+\mathrm{CH}_{3} \bullet$ & - & 1.39 & $1.00^{*}$ & -1.18 & $\mathrm{H}_{2}$ evolution \\
\hline $6 \mathrm{f}$ & ${ }^{3} \mathrm{I} 4+\mathrm{CH}_{3} \bullet \rightarrow{ }^{1} \mathrm{FS}_{2} \mathrm{~b}^{\prime}+\mathrm{CH}_{3} \bullet$ & 1.97 & -1.47 & 1.81 & 0.53 & $\begin{array}{l}\text { Transfer of } 2 \text { nd } \mathrm{H} \text { of } \\
\text { methane to }\left(\mathrm{C}_{t 1}\right) \text { of } \\
\mathrm{FeC}_{3}\end{array}$ \\
\hline $6 g$ & ${ }^{3} \mathrm{I}_{4}{ }^{\prime}+\mathrm{CH}_{3} \bullet \rightarrow{ }^{1} \mathrm{FS}_{2} \mathrm{~b}^{\prime}+\mathrm{CH}_{3} \bullet$ & 0.99 & 0.84 & 1.20 & 0.84 & $\begin{array}{l}\text { Transfer of } 2 \mathrm{nd} \mathrm{H} \text { of } \\
\text { methane to }\left(\mathrm{C}_{t 2}\right) \text { of } \\
\mathrm{FeC}_{3}\end{array}$ \\
\hline $7 f(7 g)$ & ${ }^{1} \mathrm{FS}_{2} \mathrm{~b}^{\prime}+\mathrm{CH}_{3} \bullet \rightarrow{ }^{1} \mathrm{I}^{2} \mathrm{~b}^{\prime}+\mathrm{CH}_{3} \bullet+\mathrm{H}_{2}$ & - & 1.35 & 0.93 & -1.25 & $\mathrm{H}_{2}$ evolution \\
\hline $8 \mathrm{f}(8 \mathrm{~g})$ & $\begin{array}{l}{ }^{1} \mathrm{I}_{5} \mathrm{~b}^{\prime}+\mathrm{CH}_{3} \bullet+\mathrm{H}_{2} \rightarrow{ }^{1} \mathrm{FeC}_{4} \mathrm{H} @ \mathrm{SiO}_{2} \\
+2 \mathrm{H}_{2}+\mathrm{CH}_{3} \bullet\end{array}$ & - & 1.81 & 1.49 & -0.69 & $\mathrm{H}_{2}$ evolution \\
\hline $7 \mathrm{~h}$ & ${ }^{4} \mathrm{FS} 2+2 \mathrm{CH}_{3} \bullet \rightarrow{ }^{2} \mathrm{I}_{5} \mathrm{a}^{\prime \prime}+2 \mathrm{CH}_{3} \bullet$ & NA & 0.45 & NA & 0.47 & $\begin{array}{l}\text { H-transfer from } \mathrm{C}_{\mathrm{t} 2} \text { to } \\
\mathrm{C}_{\mathrm{c}} \text { of } \mathrm{FeC}_{3}\end{array}$ \\
\hline $8 \mathrm{~h}$ & ${ }^{2} \mathrm{I}_{5} \mathrm{a}^{\prime \prime}+2 \mathrm{CH}_{3} \bullet \rightarrow{ }^{4} \mathrm{I}_{6 \mathrm{a}^{\prime}}+2 \mathrm{CH}_{3} \bullet$ & NA & -0.72 & NA & -0.69 & $\begin{array}{l}\text { H-transfer from } \mathrm{C}_{\mathrm{c}} \text { to } \\
\mathrm{C}_{\mathrm{t} 1} \text { of } \mathrm{FeC}_{3}\end{array}$ \\
\hline $9 \mathrm{~h}(7 \mathrm{~d})$ & ${ }^{4} \mathrm{I} \mathrm{a}^{\prime}+2 \mathrm{CH}_{3} \bullet \rightarrow{ }^{4} \mathrm{IS}+\mathrm{H}_{2}+2 \mathrm{CH}_{3} \bullet$ & - & 2.11 & 1.69 & -0.49 & $\mathrm{H}_{2}$ evolution \\
\hline
\end{tabular}




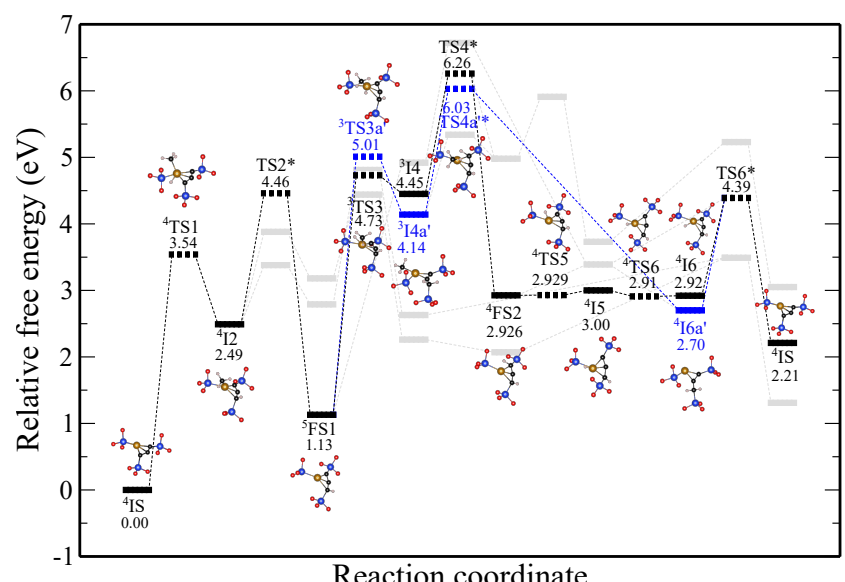

(a)

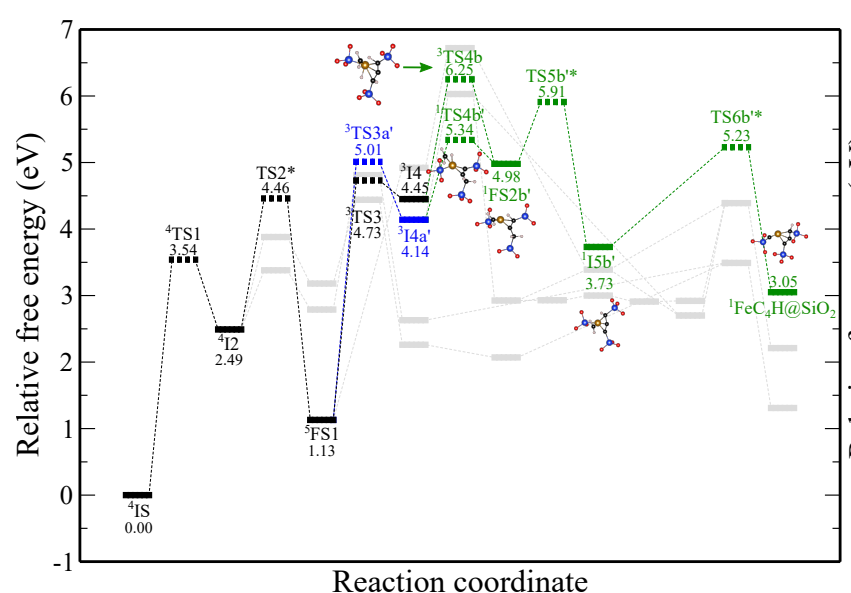

(c)

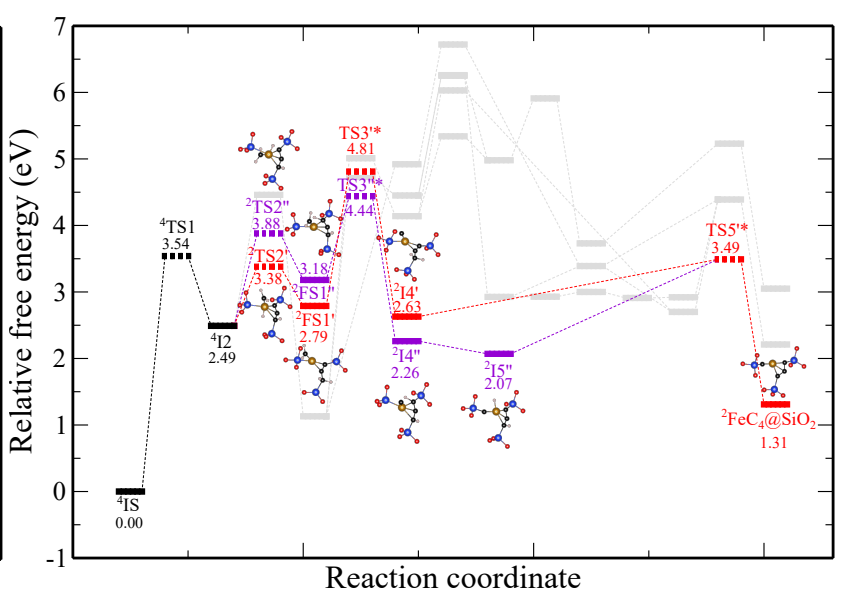

(b)

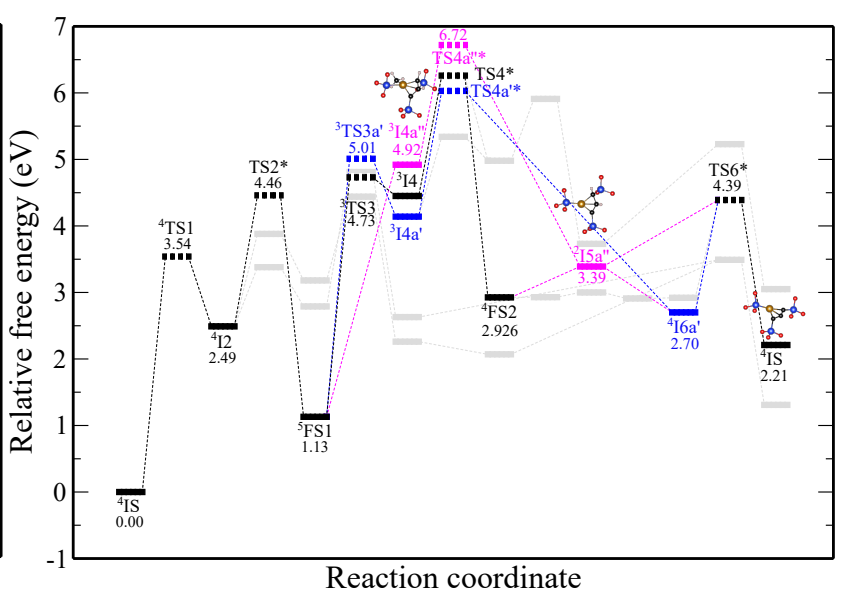

(d)

Figure 4: Detailed free energy surface showing various elementary pathways which can contribute to the overall reaction: (a) energy surfaces shown in black and blue color represent two pathways - R1 and R2 - (also highlighted in other subfigures for comparison) which contribute significantly in the overall reactions, (b) energy surfaces which may lead to formation of $\mathrm{FeC}_{4} @ \mathrm{SiO}_{2}$, (c) energy surfaces which lead to $\mathrm{FeC}_{4} \mathrm{H} @ \mathrm{SiO}_{2}$ formation, and (d) a less significant pathway that leads to $\mathrm{C}-\mathrm{H}$ activation. Solid ( broken ) bold horizontal lines represent various intermediates (TSs). Active site geometries of intermediates/TSs are shown in the vicinity of the corresponding energy levels. The TSs marked with an additional asterisk $(*)$ symbol are estimated by associated enthalpy change of the reactions, and hence, no active site geometries are shown in such cases. The difference in free energy of the initial and final states of the overall reaction corresponds to the reaction free energy of the reaction under the reaction conditions of $1223 \mathrm{~K}$ and 1 atm: $2 \mathrm{CH}_{4} \rightarrow 2 \mathrm{CH}_{3} \bullet+\mathrm{H}_{2}$. 
Table 2: Important bond-distances and bond-angles of the TSs associated to the elementary relation steps involving $\mathrm{C}-\mathrm{H}$ bond breaking, $\mathrm{CH}_{4} \rightarrow \mathrm{CH}_{3}+\mathrm{H}$

\begin{tabular}{ccccc}
\hline & \multicolumn{3}{c}{ Bond Distance $(\AA)$} & Bond Angle $\left(^{\circ}\right)$ \\
& Fe-C $_{\mathrm{m}}$ & Fe- $\mathrm{H}_{\mathrm{A}}$ & $\mathrm{C}_{\mathrm{m}}-\mathrm{H}_{\mathrm{A}}$ & $\mathrm{C}_{\mathrm{m}}-\mathrm{Fe}-\mathrm{H}_{\mathrm{A}}$ \\
\hline TS1 & 1.95 & 1.54 & 2.96 & 115.74 \\
TS3 & 2.06 & 1.52 & 1.53 & 47.64 \\
TS3a' $^{\prime}$ & 2.01 & 1.51 & 1.62 & 52.63 \\
TS2 $^{\prime}$ & 1.72 & 1.53 & 2.38 & 93.49 \\
TS2 $^{\prime \prime}$ & 1.78 & 1.46 & 2.07 & 79.00 \\
TS4b & 1.80 & 1.57 & 2.51 & 95.97 \\
TS4b $^{\prime}$ & 1.68 & 1.50 & 1.58 & 59.43 \\
\hline
\end{tabular}
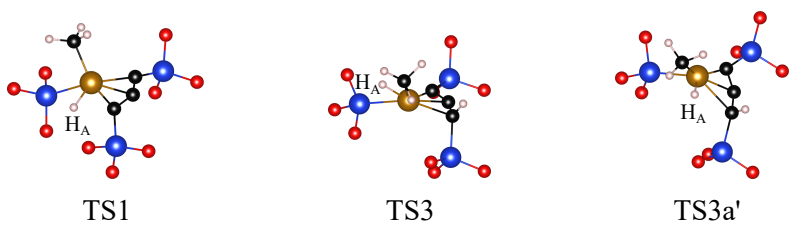

(a)

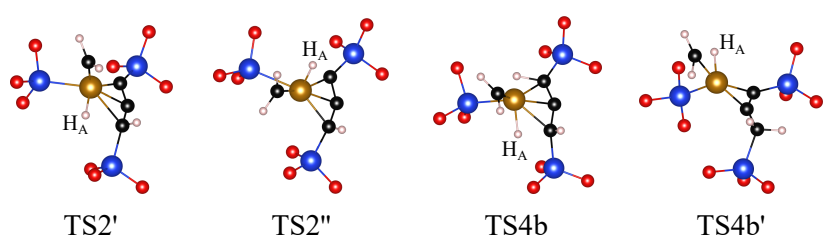

(b)

Figure 5: Transition states associated to elementary reaction pathways involving $\mathrm{C}-\mathrm{H}$ bond rupture. (a) TS1, TS3 and TS3a' are associated to reactions $2,5 \mathrm{a}$ and $5 \mathrm{~d}$ in Table 1 , respectively; (b) TS2', TS2", TS4b and TS4b' are associated to reactions $3 \mathrm{~b}, 3 \mathrm{c}, 6 \mathrm{f}$ and $6 \mathrm{~g}$ in Table 1 , respectively.

to $\mathrm{Fe}$ atom $\left({ }^{4} \mathrm{I} 5\right)$. In the second step $\left({ }^{4} \mathrm{I} 5\right.$ $\left.\rightarrow{ }^{4} \mathrm{I} 6\right)$, $\mathrm{H}$ atom transferred to Fe atom reorients itself to come in proximity of the $\mathrm{H}$ atom attached to $\mathrm{C}_{\mathrm{t} 1}$. Then, in the final step $\left({ }^{4} \mathrm{I} 6 \rightarrow{ }^{4} \mathrm{IS}\right)$, these two $\mathrm{H}$ atoms evolve as the $\mathrm{H}_{2}$ molecule, giving back the initial state ${ }^{4}$ IS. Associated reaction energies of the $\mathrm{H}$-transfer, $\mathrm{H}$ rearrangement and $\mathrm{H}_{2}$-evolution reaction steps are estimated as $0.004 \mathrm{eV},-0.08 \mathrm{eV}$ and -0.71 $\mathrm{eV}$, respectively, whereas the corresponding reaction barriers are $0.003 \mathrm{eV},-0.10 \mathrm{eV}$ and 1.47 $\mathrm{eV}$, respectively. Note that the negative barrier is due to the fact that the positive change in electronic enthalpy (DFT energy) is smaller in magnitude than the negative changes in $\mathrm{ZPE}$ and thermal correction to enthalpy at $1223 \mathrm{~K}$. As a consequence, the H-rearrangement reaction becomes barrierless.

Alternatively, the intermediate ${ }^{4} \mathrm{I}_{6} \mathrm{a}^{\prime}$ undergoes one step $\mathrm{H}_{2}$-evolution reaction $\left({ }^{4} \mathrm{I} \mathrm{a}^{\prime} \rightarrow\right.$ ${ }^{4} \mathrm{IS}$ ), in which $\mathrm{CH}_{2}$ group yields its $\mathrm{H}$ atoms in the form of $\mathrm{H}_{2}$ molecule, leading to the regeneration of initial state. Transition barrier and reaction energy of this reaction are estimated as $1.69 \mathrm{eV}$ and $-0.49 \mathrm{eV}$, respectively (see Fig. $4(\mathrm{a}))$.

One additional pathway which starts from the state ${ }^{4} \mathrm{FS} 2$ and connects it to the state ${ }^{4} \mathrm{I}_{6 \mathrm{a}}$ ' is as follows: ${ }^{4} \mathrm{FS} 2 \rightarrow{ }^{4} \mathrm{I} 5 \mathrm{a}^{\prime \prime} \rightarrow{ }^{4} \mathrm{I}_{6 \mathrm{a}}$. This step is less likely to occur as ${ }^{4} \mathrm{FS} 2 \rightarrow{ }^{4} \mathrm{I} 5 \mathrm{a}^{\prime \prime}$ competes with $\mathrm{H}$-transfer and H-rearrangement $\left({ }^{4} \mathrm{FS} 2 \rightarrow\right.$ $\left.{ }^{4} \mathrm{I} 5 \rightarrow{ }^{4} \mathrm{I} 6^{\prime \prime}\right)$ which are highly likely steps. Additoinally, ${ }^{4} \mathrm{I} 5 \rightarrow{ }^{4} \mathrm{I}_{6} \mathrm{a}^{\prime}$ or ${ }^{4} \mathrm{I} 6 \rightarrow{ }^{4} \mathrm{I}_{6} \mathrm{a}^{\prime}$ may ocuur before $\mathrm{H}_{2}$ evolution due to extra stability of ${ }^{4} \mathrm{I} 6 \mathrm{a}{ }^{\prime}$.

\section{Conversion of $\mathrm{FeC}_{2} @ \mathrm{SiO}_{2}$ sites into $\mathrm{FeC}_{3} @ \mathrm{SiO}_{2}$ sites}

In situ formation of $\mathrm{FeC}_{3}$ from $\mathrm{FeC}_{2}$ is exergonic and the reaction free energy is -0.94 $\mathrm{eV}$. The reaction mechanism (shown in Fig. 6) for $\mathrm{FeC}_{3}$ formation involves two successive C$\mathrm{H}$ bond activations from the same methane molecule, followed by the evolution of two $\mathrm{H}_{2}$ molecules. The activation barrier for first $\mathrm{C}-\mathrm{H}$ activation is calculated to be $3.52 \mathrm{eV}$. Two possibilities arise for the $\mathrm{H}$ transfer during second 
$\mathrm{C}-\mathrm{H}$ activation. One results in the geometry in which both $\mathrm{H}$ atoms are bonded to the same $\mathrm{C}$ atom of $\mathrm{FeC}_{2}\left({ }^{2} \mathrm{rFS}^{\prime}\right)$ and other results in the geometry in which one $\mathrm{H}$ is bonded to each $\mathrm{C}$ of $\mathrm{FeC}_{2}\left({ }^{2} \mathrm{rFS}^{\prime \prime}\right.$, mechanism shown in Fig $\mathrm{S} 1$ in supplementary information). The reaction free energies (see Fig 7 and Fig 8) show that formation of ${ }^{2} \mathrm{rFS}^{\prime \prime}$ is endergonic reaction ( 0.28 $\mathrm{eV})$, whereas formation of ${ }^{2} \mathrm{rFS} 1$ ' is exergonic $(-0.06 \mathrm{eV})$. Although, the formation of ${ }^{2} \mathrm{rSS}^{\prime}$ is thermodynamically more favourable than that of ${ }^{2} \mathrm{rFS1}$ ", it passes through a kinetic barrier with energy $0.16 \mathrm{eV}$ higher than that for ${ }^{2} \mathrm{rFS} 1 "$.

An alternative to $\mathrm{C}-\mathrm{H}$ activation of the adsorbed methyl group involves the exergonic methyl radical evolution via ${ }^{2} \mathrm{rI} 2 \rightarrow{ }^{3} \mathrm{rFS} 1$. In fact, Guo et al. ${ }^{25}$ eliminated the formation of $\mathrm{FeC}_{3}$ by comparing the thermodynamic feasibility of methyl radical evolution with the formation of ${ }^{2} \mathrm{rFS} 1$ ", concluding that the former is more likely given that its exergonic nature. However, the methyl radical evolution is kinetically hindered due to a high barrier (free energy of $\mathrm{rTS}^{*}$ is $0.48 \mathrm{eV}$ higher than that of ${ }^{2} \mathrm{rTS}^{\prime}$ ) on free energy surface. Instead, at the reaction conditions, it is more likely that $\mathrm{C}-\mathrm{H}$ activation of the adsorbed methyl group would take place via the formation of ${ }^{2} \mathrm{rFS}^{\prime}$ since this step has a lower activation barrier and is also exergonic. Given the overall lower free energy of the embedded $\mathrm{FeC}_{3}$, this pathway would be all the more preferred. It is important to note that this possibility was not considered by Guo et $a l .{ }^{25}$ Our detailed thermodynamic analysis clearly indicates that $\mathrm{FeC}_{2} @ \mathrm{SiO}_{2}$ converts to $\mathrm{FeC}_{3} @ \mathrm{SiO}_{2}$ at reaction conditions. This conclusion is further strengthened by the kinetic analysis presented below. Hence, it is important to understand the catalytic activity of $\mathrm{FeC}_{3} @ \mathrm{SiO}_{2}$ for methane conversion.

\section{Dominant pathways on $\mathrm{FeC}_{3} @ \mathrm{SiO}_{2}$}

Based on the thermodynamic feasibility of the elementary reactions, their activation barriers, and the stability of intermediates involved, the two dominant pathways of $\mathrm{CH}_{4}$ activation at elevated temperature are as follows:

R1: ${ }^{4} \mathrm{IS} \rightarrow{ }^{4} \mathrm{I} 1 \rightarrow\left[{ }^{4} \mathrm{TS} 1\right] \rightarrow{ }^{4} \mathrm{I} 2 \rightarrow\left[\mathrm{TS}^{*}\right] \rightarrow$

$$
\begin{aligned}
& { }^{5} \mathrm{FS} 1 \rightarrow{ }^{3} \mathrm{I} 3 \rightarrow\left[{ }^{3} \mathrm{TS} 3\right] \rightarrow{ }^{3} \mathrm{I} 4 \rightarrow\left[\mathrm{TS} 4^{*}\right] \rightarrow \\
& { }^{4} \mathrm{FS} 2 \rightarrow\left[{ }^{4} \mathrm{TS} 5\right] \rightarrow{ }^{4} \mathrm{I} 5 \rightarrow\left[{ }^{4} \mathrm{TS} 6\right] \rightarrow{ }^{4} \mathrm{I} 6 \rightarrow \\
& {\left[\mathrm{TS} 7^{*}\right] \rightarrow{ }^{4} \mathrm{IS} .}
\end{aligned}
$$
R2: ${ }^{4} \mathrm{IS} \rightarrow{ }^{4} \mathrm{I} 1 \rightarrow\left[{ }^{4} \mathrm{TS} 1\right] \rightarrow{ }^{4} \mathrm{I} 2 \rightarrow\left[\mathrm{TS}^{*}\right]$ $\rightarrow{ }^{5} \mathrm{FS} 1 \rightarrow{ }^{3} \mathrm{I} 3 \rightarrow\left[{ }^{3} \mathrm{TS} \mathrm{a}^{\prime}\right] \rightarrow{ }^{3} \mathrm{I} \mathrm{a}^{\prime} \rightarrow$ $\left[\mathrm{TS} \mathrm{a}^{\prime *}\right] \rightarrow{ }^{4} \mathrm{I} \mathrm{a}^{\prime} \rightarrow\left[\mathrm{TS} 7^{*}\right] \rightarrow{ }^{4} \mathrm{IS}$.

Furthermore, if the endergonic transfer of $\mathrm{H}$ atom from the Fe-bound methyl group to the $\mathrm{C}$ atoms of $\mathrm{FeC}_{3}\left({ }^{4} \mathrm{I} 2 \rightarrow{ }^{2} \mathrm{FS}^{\prime} /{ }^{2} \mathrm{FS}^{\prime \prime}\right)$ is presumed to occur at reaction conditions then the $\mathrm{FeC}_{4} @ \mathrm{SiO}_{2}$ formation becomes favourable using either of the following paths:

$$
\begin{aligned}
\text { R3: } & { }^{4} \mathrm{IS} \rightarrow{ }^{4} \mathrm{I} 1 \rightarrow\left[{ }^{4} \mathrm{TS} 1\right] \rightarrow{ }^{4} \mathrm{I} 2 \rightarrow\left[{ }^{2} \mathrm{TS}^{\prime}\right] \\
& \rightarrow{ }^{2} \mathrm{FS}^{\prime} \rightarrow\left[\mathrm{TS}^{\prime *}\right] \rightarrow{ }^{2} \mathrm{I}^{\prime} \rightarrow\left[\mathrm{TS}^{\prime *}\right] \rightarrow \\
& { }^{2} \mathrm{FeC}_{4} \mathrm{SSiO}_{2} .
\end{aligned}
$$

$$
\begin{aligned}
\text { R4: } & { }^{4} \mathrm{IS} \rightarrow{ }^{4} \mathrm{I} 1 \rightarrow\left[{ }^{4} \mathrm{TS} 1\right] \rightarrow{ }^{4} \mathrm{I} 2 \rightarrow\left[{ }^{2} \mathrm{TS}^{\prime \prime}\right] \\
& \rightarrow{ }^{2} \mathrm{FS}^{\prime \prime} \rightarrow\left[\mathrm{TS}^{\prime *}\right] \rightarrow{ }^{2} \mathrm{I}^{\prime \prime} \rightarrow{ }^{2} \mathrm{I}^{\prime \prime} \rightarrow \\
& {\left[{ }^{2} \mathrm{TS}^{\prime *}\right] \rightarrow{ }^{2} \mathrm{FeC}_{4} @ \mathrm{SiO}_{2} . }
\end{aligned}
$$

\section{Results of the kinetic model}

The kinetics of the methane activation on $\mathrm{FeC}_{3}$ depends in a characteristic way on the methane partial pressure. There is a low pressure limit in which the overall activity is proportional to the pressure. The activity increases and then levels off when the pressure is increased. There is a high pressure limit in which the activity is constant. We present here the results for both limits separately.

The net rates (i.e., the difference between the rates of the forward and reverse reaction) for the elementary reactions ${ }^{4} \mathrm{IS} \rightarrow{ }^{4} \mathrm{I} 1 \rightarrow{ }^{4} \mathrm{I} 2 \rightarrow$ ${ }^{3} \mathrm{I} 3$ that are common to paths $\mathrm{R} 1$ and $\mathrm{R} 2$ are necessarily the same at steady state because of mass balance. The same holds for the rates of the elementary reactions ${ }^{3} \mathrm{I} 3 \rightarrow{ }^{3} \mathrm{I} 4 \rightarrow{ }^{4} \mathrm{FS} 2 \rightarrow$ ${ }^{4} \mathrm{I} 5 \rightarrow{ }^{4} \mathrm{I} 6 \rightarrow{ }^{4} \mathrm{IS}$ in $\mathrm{R} 1$ and for the rates of the elementary reactions ${ }^{3} \mathrm{I} 3 \rightarrow{ }^{3} \mathrm{I}_{4} \mathrm{a}^{\prime} \rightarrow{ }^{4}{\mathrm{I} 6 \mathrm{a}^{\prime} \rightarrow{ }^{4} \mathrm{IS}}$ in R2 as well. Moreover, the sum of the net rates of these two branches is equal to net rate of ${ }^{4} \mathrm{IS} \rightarrow{ }^{4} \mathrm{I} 1 \rightarrow{ }^{4} \mathrm{I} 2 \rightarrow{ }^{3} \mathrm{I} 3$. Consequently, exactly half of the methyl radicals are formed by the ${ }^{4} \mathrm{I} 2 \rightarrow{ }^{5} \mathrm{FS} 1+\mathrm{CH}_{3} \bullet$ reaction. The second methyl radical is either formed by ${ }^{3} \mathrm{I} 4 \rightarrow$ ${ }^{4} \mathrm{FS} 2+\mathrm{CH}_{3} \bullet$ or by ${ }^{3} \mathrm{I}_{4} \mathrm{a}^{\prime} \rightarrow{ }^{4} \mathrm{I}_{6} \mathrm{a}^{\prime}+\mathrm{CH}_{3} \bullet$. It 

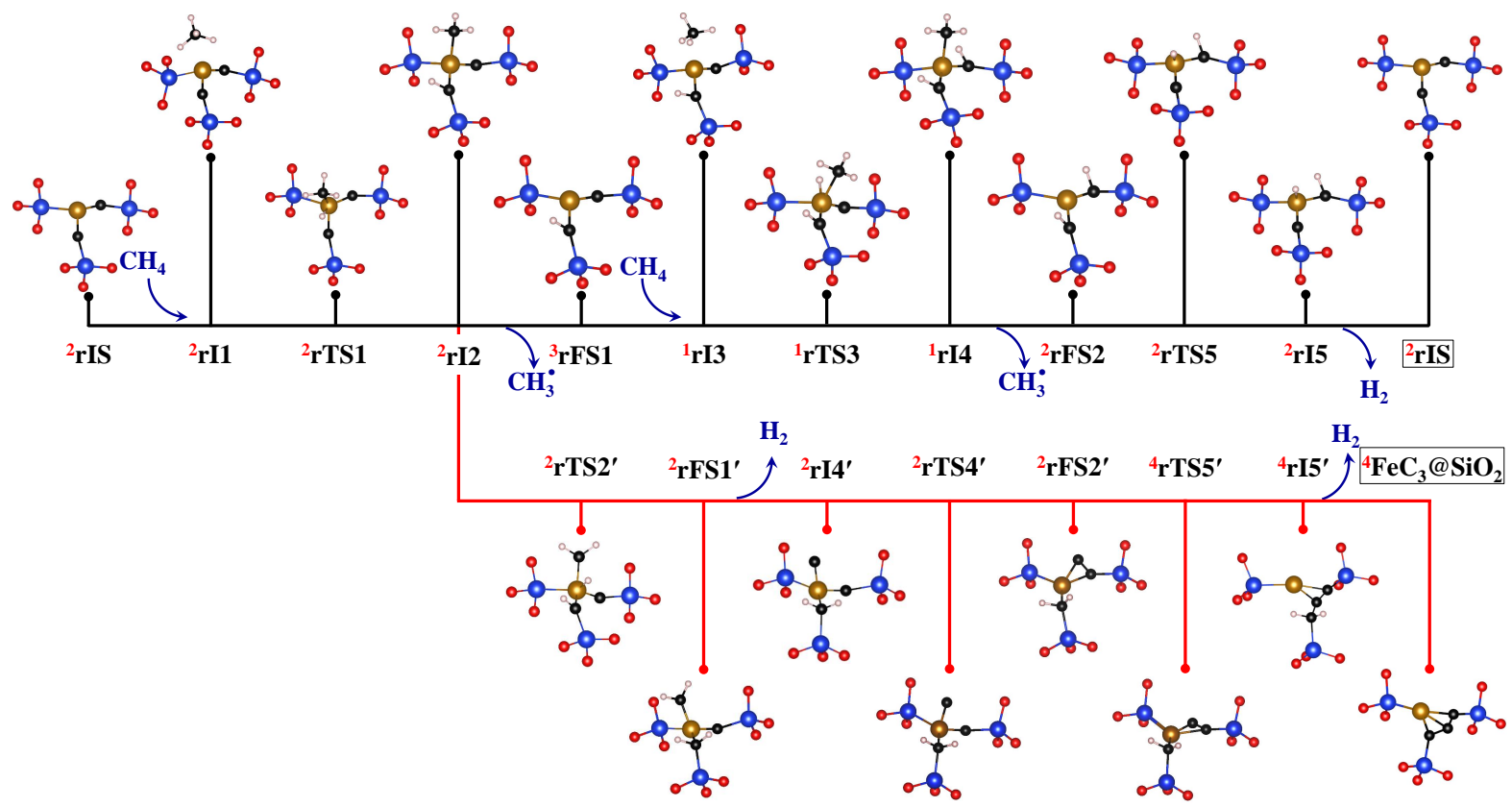

Figure 6: Reaction pathways for methane conversion on $\mathrm{FeC}_{2} @ \mathrm{SiO}_{2}$ surface. The red color line represents the pathway which leads to the $\mathrm{FeC}_{3}$ formation. Path with black line is same as the path studied by Guo et al. ${ }^{25}$ The numbers in red superscript are the spin multiplicity of corresponding states. Blue, red, dark brown, black and white spheres represent $\mathrm{Si}, \mathrm{O}, \mathrm{Fe}, \mathrm{C}$ and $\mathrm{H}$ respectively.

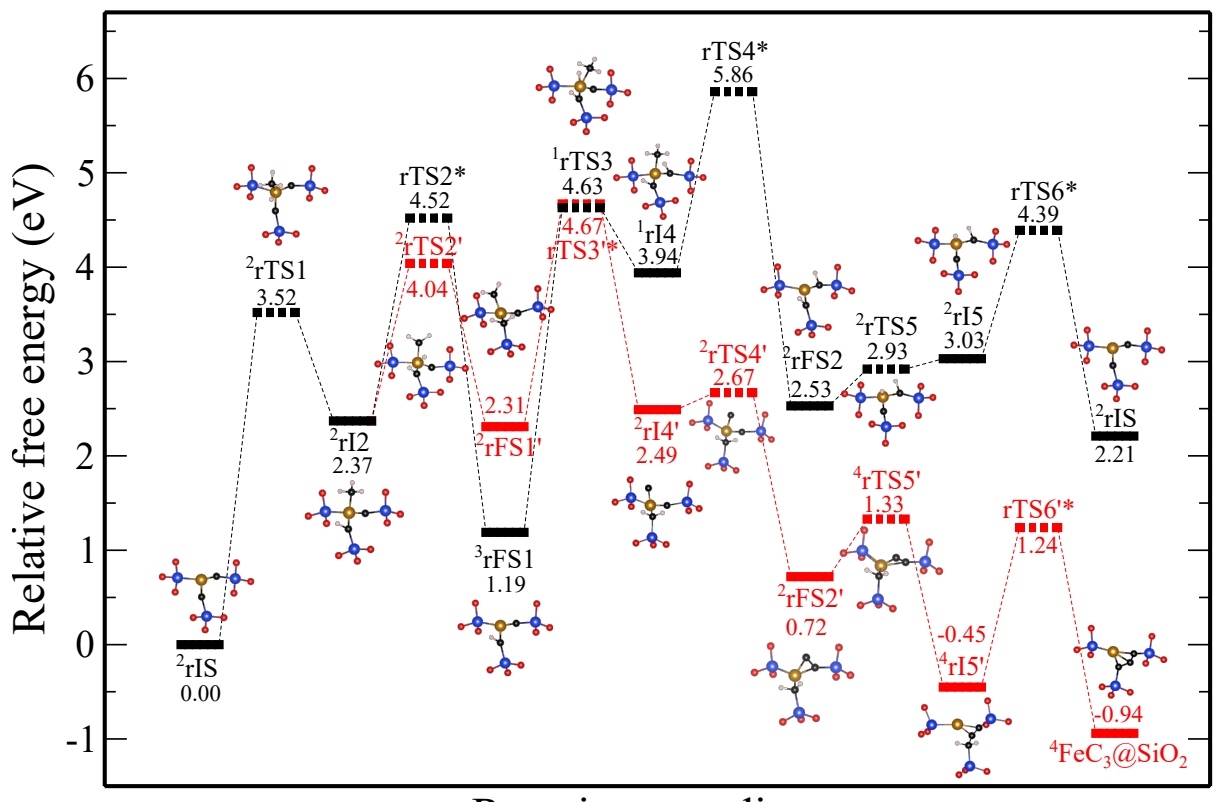

Reaction coordinate

Figure 7: Free energy profile for methane conversion on $\mathrm{FeC}_{2} @ \mathrm{SiO}_{2}$ surface. The red curve represents the pathway which leads to the $\mathrm{FeC}_{3}$ formation. Path with black line is same as the path studied by Guo et al. ${ }^{25}$ The colored numbers represented the free energy (in eV) of corresponding states. The difference in free energy of the initial and final states of the overall reaction corresponds to the reaction free energy of the reaction: $2 \mathrm{CH}_{4} \rightarrow 2 \mathrm{CH}_{3} \bullet+\mathrm{H}_{2}$. 


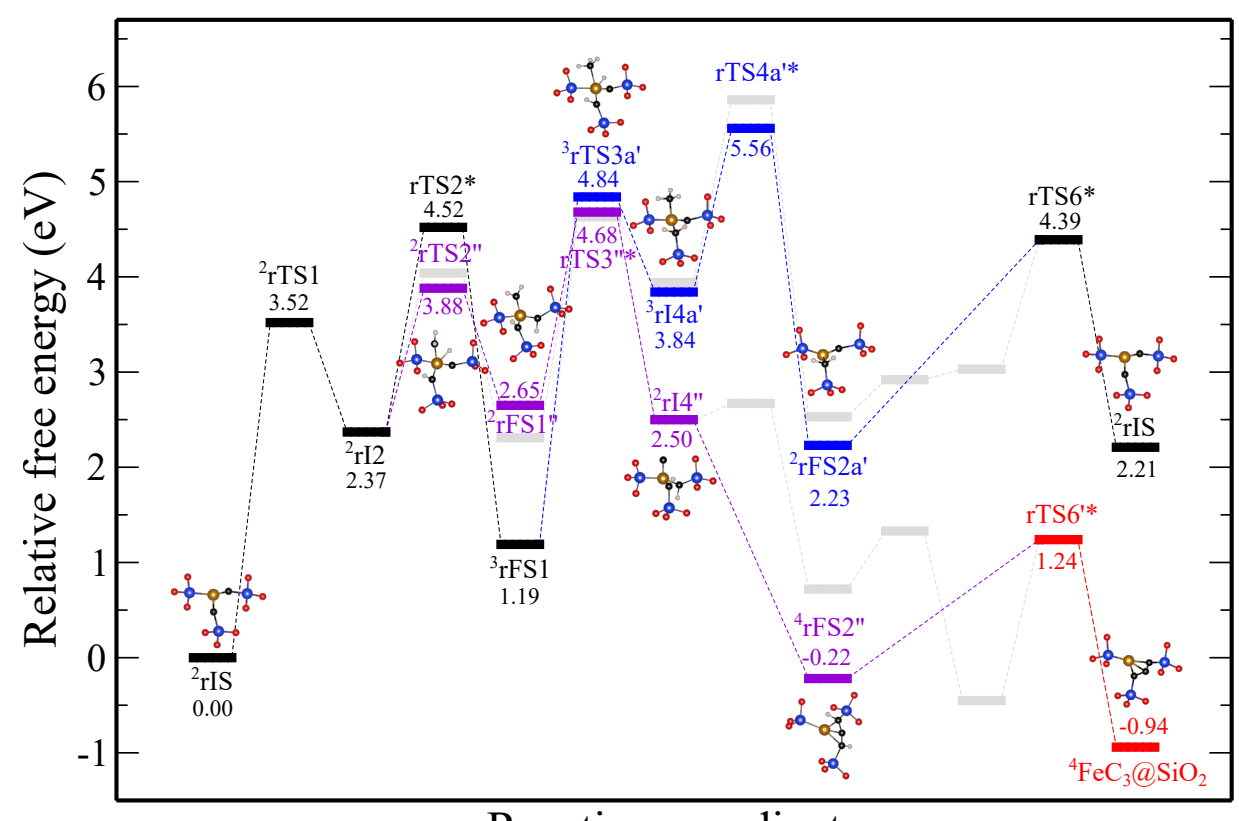

Reaction coordinate

Figure 8: Free energy profile for methane conversion on $\mathrm{FeC}_{2} @ \mathrm{SiO}_{2}$ surface. The color of curves are in line with the Fig S1 in SI. The colored numbers represented the free energy (in eV) of corresponding states. The difference in free energy of the initial and final states of the overall reaction corresponds to the reaction free energy of the reaction: $2 \mathrm{CH}_{4} \rightarrow 2 \mathrm{CH}_{3} \bullet+\mathrm{H}_{2}$.

turns out that the latter reaction has a rate that is about nine times the former, both in the low and the high pressure limit. This factor agrees quantitively with $\exp \left(\Delta E_{\mathrm{TS}} / k_{\mathrm{B}} T\right)$ with $\Delta E_{\mathrm{TS}}$ being the difference in energies of the transition states TS4* and TS4a ${ }^{*}$. This factor of nine is necessarily then also found for the formation of hydrogen via the two branches since the overall rate is dictated by the transition state with highest energy. i.e. TS4a ${ }^{\prime *}$.

We have determined the rate-determining steps by halving the rate constants for forward (and reverse, if applicable) reactions and looking at how this affects the activity. Table 3 shows that the rate-determining steps are the same in both methane pressure limits although their relative importance varies. Changing the rate constants for forward and reverse reactions by a half corresponds to changing the energy of the transition state of about $0.07 \mathrm{eV}$ at $1223 \mathrm{~K}$. However, there was no effect whatsoever on the activity when the rates of the reversible reactions were altered. It is only the irreversible reactions forming the methyl radical and hydrogen that have an effect, although that of reac- tions forming hydrogen is very minor. Changing the rate constant of the latter changes the overall activity by only a few percent at most. The effect of the methyl radical forming reaction ${ }^{3} \mathrm{I} 4 \rightarrow{ }^{4} \mathrm{FS} 2+\mathrm{CH}_{3} \bullet$ is also of that magnitude. This is due to the fact that this reaction contributes only about $5 \%$ to the total amount of methyl radicals formed.

The important rate-determining reactions are ${ }^{4} \mathrm{I} 2 \rightarrow{ }^{5} \mathrm{FS} 1+\mathrm{CH}_{3} \bullet$ and ${ }^{3} \mathrm{I}_{4} \mathrm{a}^{\prime} \rightarrow{ }^{4} \mathrm{I}_{6 \mathrm{a}}{ }^{\prime}+\mathrm{CH}_{3} \bullet$. The latter is the only rate-determining reaction in the low pressure limit. The overall activity is reduced by $44 \%$ when its rate constant is halved. The former reaction however is the more important one in the high pressure limit. Overall activity is reduced by $38 \%$ if its rate constant if halved, compared to $21 \%$ for halving the rate constant of ${ }^{3} \mathrm{I}_{4} \mathrm{a}^{\prime} \rightarrow{ }^{4} \mathrm{I} \mathrm{a}^{\prime}+\mathrm{CH}_{3}$. This may be surprising as the energy of the transition state TS2* is much lower than that of $\mathrm{TS}_{4} \mathrm{a}^{*}$. We think that the reason for the importance of ${ }^{4} \mathrm{I} 2 \rightarrow{ }^{5} \mathrm{FS} 1+\mathrm{CH}_{3} \bullet$ in the high pressure limit is that a small fraction of the adsorption sites for methane are vacant as shown in Table 4. Changing the rate constant of 
Table 3: Reduction of the rates with which the methyl radical and hydrogen is produced when the rate constant of one forward reaction (and the corresponding reverse reaction, if present) is halved.

\begin{tabular}{crr}
\hline & \multicolumn{2}{c}{ Methane pressure limit } \\
Reaction & Low & High \\
\hline${ }^{4} \mathrm{I} 1 \rightleftharpoons{ }^{4} \mathrm{I} 2$ & $0 \%$ & $0 \%$ \\
${ }^{4} \mathrm{I} 2 \rightarrow{ }^{5} \mathrm{FS} 1+\mathrm{CH}_{3} \bullet$ & $0 \%$ & $38 \%$ \\
${ }^{3} \mathrm{I} 3 \rightleftharpoons{ }^{3} \mathrm{I} 4$ & $0 \%$ & $0 \%$ \\
${ }^{3} \mathrm{I} 4 \rightarrow{ }^{4} \mathrm{FS} 2+\mathrm{CH}_{3} \bullet$ & $5 \%$ & $2 \%$ \\
${ }^{4} \mathrm{FS} 2 \rightleftharpoons{ }^{4} \mathrm{I} 5$ & $0 \%$ & $0 \%$ \\
${ }^{4} \mathrm{I} 5 \rightleftharpoons{ }^{4} \mathrm{I} 6$ & $0 \%$ & $0 \%$ \\
${ }^{4} \mathrm{I} 6 \rightarrow{ }^{4} \mathrm{IS}+\mathrm{H}_{2}$ & $0 \%$ & $0 \%$ \\
${ }^{3} \mathrm{I} 3 \rightleftharpoons{ }^{3} \mathrm{Ia}^{\prime}$ & $0 \%$ & $0 \%$ \\
${ }^{3} \mathrm{I}^{\prime} \mathrm{a}^{\prime} \rightarrow{ }^{4} \mathrm{I} 6 \mathrm{a}^{\prime}+\mathrm{CH}_{3} \bullet$ & $44 \%$ & $21 \%$ \\
${ }^{4} \mathrm{I} \mathrm{a}^{\prime} \rightarrow{ }^{4} \mathrm{IS}+\mathrm{H}_{2}$ & $0 \%$ & $4 \%$ \\
\hline
\end{tabular}

${ }^{4} \mathrm{I} 2 \rightarrow{ }^{5} \mathrm{FS} 1+\mathrm{CH}_{3} \bullet$ affects the concentration of ${ }^{4} \mathrm{I} 2$ and indirectly, via the rapid equilibrium ${ }^{4} \mathrm{IS} \rightleftharpoons{ }^{4} \mathrm{I} 2$, also ${ }^{4} \mathrm{IS}$ and hence the overall activity.

In order to compare simulation results with the experimental turnover frequencies (TOFs) it is essential to know values of a few parameters, especially the sticking coefficient of methane on the catalyst under study. Brass and Ehlrich $^{49}$ carried out experimental studies on chemisorption of methane on evaporated films of rhodium and provided a temperature dependence of the sticking coefficient. Extrapolating their correlation to high temperatures, we estimate a sticking coefficient of $2.6 \times 10^{-1} \mathrm{~s}^{-1}$. In the absence of a known value for $\mathrm{FeC}_{x} @ \mathrm{SiO}_{2}$ catalysts, we assume it to be on the same order of magnitude as that for Rh. With this value of sticking coefficient, the microkinetic modelling leads to the TOF of $\sim 10 \mathrm{~s}^{-1}$ for methane activation for $\mathrm{FeC}_{3} @ \mathrm{SiO}_{2}$ catalyst at $\mathrm{P}=1$ bar and $\mathrm{T}=1223 \mathrm{~K}$. To get experimental TOFs, the data provided by Guo et al. ${ }^{25}$ was utilized to estimate an active site density of $0.254 \mathrm{~nm}^{-2}$ (for isolated $\mathrm{FeC}_{x}$ centres) based on the high resolution TEM image (details in SI). This site density resulted in an estimated catalyst TOF of $\sim 10 \mathrm{~s}^{-1}$ at $1223 \mathrm{~K}$, which is
Table 4: Relative concentration of the various structures during reaction at steady state. The sum of the relative concentrations is set equal to one.

\begin{tabular}{crr}
\hline & \multicolumn{2}{c}{ Methane pressure limit } \\
Structure & Low & High \\
\hline${ }^{4} \mathrm{IS}$ & $1.7 \cdot 10^{-2}$ & $1.1 \cdot 10^{-3}$ \\
${ }^{4} \mathrm{I} 1$ & $9.3 \cdot 10^{-9}$ & $6.2 \cdot 10^{-5}$ \\
${ }^{4} \mathrm{I} 2$ & $7.0 \cdot 10^{-6}$ & $6.1 \cdot 10^{-1}$ \\
${ }^{5} \mathrm{FS} 1$ & $9.8 \cdot 10^{-1}$ & $6.5 \cdot 10^{-2}$ \\
${ }^{3} \mathrm{I} 3$ & $3.1 \cdot 10^{-7}$ & $2.0 \cdot 10^{-3}$ \\
${ }^{3} \mathrm{I} 4$ & $2.0 \cdot 10^{-6}$ & $1.3 \cdot 10^{-2}$ \\
${ }^{4} \mathrm{FS} 2$ & $7.6 \cdot 10^{-8}$ & $5.1 \cdot 10^{-4}$ \\
${ }^{4} \mathrm{I} 5$ & $3.8 \cdot 10^{-8}$ & $2.5 \cdot 10^{-4}$ \\
${ }^{4} \mathrm{I} 6$ & $8.1 \cdot 10^{-8}$ & $5.4 \cdot 10^{-4}$ \\
${ }^{3} \mathrm{I} 4 \mathrm{a}^{\prime}$ & $3.9 \cdot 10^{-5}$ & $2.6 \cdot 10^{-1}$ \\
${ }^{4} \mathrm{I} 6 \mathrm{a}^{\prime}$ & $7.0 \cdot 10^{-6}$ & $4.6 \cdot 10^{-2}$ \\
\hline
\end{tabular}

in quite good agreement with the predictions from the microkinetic model. Note that the experimental TOF is inversely proportional to site density, which means that even if the estimated site density is off (high or low) by a factor of 2 , estimates of TOF will still fall in the range of $5-20 \mathrm{~s}^{-1}$ which is in quite good agreement with our predictions.

\section{Kinetics of the conversion of $\mathrm{FeC}_{2}$ into $\mathrm{FeC}_{3}$ and $\mathrm{FeC}_{4}$}

It is clear from the energetics that $\mathrm{FeC}_{3}$ is thermodynamically more stable than $\mathrm{FeC}_{2}$ and $\mathrm{FeC}_{4}$. Kinetically things are more complex. Our kinetic models assume that the reactions that produce methyl or hydrogen are irreversible. Readsorption of methyl or hydrogen is ignored. One reason for this is that these products will be removed. Another is that the rate of readsorption depends on the partial pressure of these species which is controlled by experimental conditions. The formation of $\mathrm{FeC}_{3}$ from $\mathrm{FeC}_{2}$ and $\mathrm{FeC}_{4}$ from $\mathrm{FeC}_{3}$ involves the production of hydrogen. As a consequence, once $\mathrm{FeC}_{3}$ and then $\mathrm{FeC}_{4}$ is formed, there is no possibility to convert the system back to the structure with one fewer carbon atom. This does not change 
anything with respect to the thermodynamics for $\mathrm{FeC}_{3}$ versus $\mathrm{FeC}_{2}\left(\mathrm{FeC}_{3}\right.$ is more stable than $\mathrm{FeC}_{2}$ anyway), but it does for $\mathrm{FeC}_{4}$ versus $\mathrm{FeC}_{3}$.

Unless the formation of $\mathrm{FeC}_{4}$ is so incredibly slow that we can ignore it, the whole system will ultimately be converted into $\mathrm{FeC}_{4}$. We have to look at the highest unavoidable transition state to determine the rate with which this is formed, i.e. TS3 ${ }^{\prime \prime *}$. This should be compared to $\mathrm{TS}_{4} \mathrm{a}^{\prime *}$, the relevant transition state for the reaction on $\mathrm{FeC}_{3}$. They have energies of 4.44 and $6.03 \mathrm{eV}$, respectively. This means that the rate of formation of $\mathrm{FeC}_{4}$ is $3.6 \cdot 10^{6}$ that of the reaction.

On the other hand it seems likely that there will be at least some readsorption of hydrogen, and that the formation of $\mathrm{FeC}_{4}$ should not be regarded as a purely irreversible process. The rate of the readsorption will depend on the partial pressure of hydrogen. The endergonicity of $1.31 \mathrm{eV}$ of $\mathrm{FeC}_{4}$ with respect to $\mathrm{FeC}_{3}$ is based on a pressure of $1 \mathrm{~atm}$. A lower pressure will reduce this number, but unless it will be much lower, we still expect that $\mathrm{FeC}_{3}$ is more stable than $\mathrm{FeC}_{4}$.

In the overall reaction, the methane molecules get activated on $\mathrm{FeC}_{2} @ \mathrm{SiO}_{2}$ sites and convert them to $\mathrm{FeC}_{3} @ \mathrm{SiO}_{2}$ sites as the formation of the latter is more favorable than other competitive methyl evolution pathways on $\mathrm{FeC}_{2} @ \mathrm{SiO}_{2}$. Once $\mathrm{FeC}_{3} @ \mathrm{SiO}_{2}$ is formed, methane molecules will be activated by $\mathrm{FeC}_{3} @ \mathrm{SiO}_{2}$ leading to evolution of methyl radicals, $\mathrm{H}_{2}$ and regeneration of the catalyst.

\section{Conclusions}

In summary, we have performed a systematic study based on ab initio calculations to elucidate mechanism of methane conversion on $\mathrm{FeC}_{3} @ \mathrm{SiO}_{2}$ catalyst surface. We have identified two potential pathways which contribute vitally to the overall methane conversion. We have also analyzed the feasibility of formation of a higher carbide $\mathrm{FeC}_{4} @ \mathrm{SiO}_{2}$ that could potentially lead to coke formation. In the study, we have also identified a possible pathway by which $\mathrm{FeC}_{3} @ \mathrm{SiO}_{2}$ catalyst can be formed in situ from $\mathrm{FeC}_{2} @ \mathrm{SiO}_{2}$, in the reaction conditions described by Guo et al. ${ }^{25}$

Conclusions regarding catalytic activity of $\mathrm{FeC}_{3} @ \mathrm{SiO}_{2}$ surface, as well as, its formation from $\mathrm{FeC}_{2} @ \mathrm{SiO}_{2}$, were drawn on the basis of two fairly comprehensive free energy surfaces followed by an kinetic analysis based on microkinetic modeling, designed especially to describe methane activation on the two catalysts. In order to construct these free energy surfaces, we used free energies of intermediates and TSs of the various elementary reaction pathways involved in the overall methane conversion.

Kinetic analysis performed during the study, sheds light on a number of important aspects of the overall reaction mechanism. Firstly, it uncovers a characteristic dependence of the overall reaction mechanism on the methane partial pressure. Secondly, it establishes that the two methyl radical evolution steps act as the rate controlling steps, both in high as well in low pressure limit. This analysis also reveals that, in the given reaction conditions, conversion of silica embedded $\mathrm{FeC}_{2}$ sites into corresponding $\mathrm{FeC}_{3}$ sites is highly likely. The catalytic activity predicted in our simulations is consistent with that seen in experiments, further supporting our conclusions. This is indeed an important advancement to the present understanding of the reaction introduced by Guo et al. ${ }^{25}$ with the conversion taking place through a favorable reaction pathway, not considered in the earlier work. Similarly, $\mathrm{FeC}_{3}$ to $\mathrm{FeC}_{4}$ conversion is also possible in the given reaction conditions, but its efficiency depends on $\mathrm{H}_{2}$ partial pressure.

The mechanism explored here, encompasses a whole set of elementary reactions important to the catalytic methane conversion, such as methane adsorption, C-H bond rupture, evolution of $\mathrm{CH}_{3} \bullet$, and eventual evolution of $\mathrm{H}_{2}$ molecule resulting in the regeneration of the initial catalyst. The remarkable activity of silica embedded $\mathrm{FeC}_{2}$ clusters and gas-phase $\mathrm{FeC}_{3}^{-}$ clusters toward methane conversion has already been demonstrated experimentally in the previous studies. In the present investigation, we have considered reaction conditions similar to those described previously ${ }^{25}$ which imparts an additional credibility to the theoretical out- 
comes, as well as makes the proposed catalyst suitable for experimental utilization. Therefore, the $\mathrm{FeC}_{3}$ cluster, when embedded in silica support, can act as an excellent heterogeneous catalyst at higher temperatures yielding direct conversion of methane to higher hydrocarbons.

Acknowledgement The authors thank Shell Global Solutions International B.V. and Shell India Markets Pvt. Ltd. for providing funding for this work, and the HPC facility at IISER Bhopal, where the calculations reported in this work were carried out. M.K. acknowledges funding through the Ph.D. programme at IISER Bhopal.

\section{References}

(1) Wang, B.; Albarracín-Suazo, S.; PagánTorres, Y.; Nikolla, E. Advances in methane conversion processes. Catal. Today 2017, 285, 147 - 158, Women in Catalysis.

(2) Schwach, P.; Pan, X.; Bao, X. Direct Conversion of Methane to Value-Added Chemicals over Heterogeneous Catalysts: Challenges and Prospects. Chem. Rev. 2017, 117, 8497-8520, PMID: 28475304.

(3) Karakaya, C.; Kee, R. J. Progress in the direct catalytic conversion of methane to fuels and chemicals. Prog. Energy Combust. Sci. 2016, 55, $60-97$.

(4) Yang, J.; Ma, W.; Chen, D.; Holmen, A.; Davis, B. H. Fischer-Tropsch synthesis: A review of the effect of $\mathrm{CO}$ conversion on methane selectivity. Appl. Catal. Al 2014, $470,250-260$.

(5) Schulz, H. Short history and present trends of Fischer-Tropsch synthesis. Appl. Catal. A 1999, 186, 3-12.

(6) Gesser, H. D.; Hunter, N. R.; Prakash, C. B. The direct conversion of methane to methanol by controlled oxidation. Chem. Rev. 1985, 85, 235-244.
(7) Alvarez-Galvan, M.; Mota, N.; Ojeda, M.; Rojas, S.; Navarro, R.; Fierro, J. Direct methane conversion routes to chemicals and fuels. Catal. Today 2011, 171, 15 23.

(8) Huang, K.; Miller, J. B.; Huber, G. W.; Dumesic, J. A.; Maravelias, C. T. A General Framework for the Evaluation of Direct Nonoxidative Methane Conversion Strategies. Joule 2018, 2, $349-365$.

(9) Schwarz, H. Chemistry with Methane: Concepts Rather than Recipes. Angew. Chem. Int. Ed. 2011, 50, 10096-10115.

(10) Greeley, J.; Mavrikakis, M. A FirstPrinciples Study of Methanol Decomposition on Pt(111). J. Am. Chem. Soc. 2002, 124, 7193-7201, PMID: 12059245.

(11) Greeley, J.; Mavrikakis, M. Competitive Paths for Methanol Decomposition on Pt(111). J. Am. Chem. Soc. 2004, 126, 3910-3919, PMID: 15038745.

(12) Liang, Z.; Li, T.; Kim, M.; Asthagiri, A.; Weaver, J. F. Low-temperature activation of methane on the $\mathrm{IrO}_{2}$ (110) surface. Science 2017, 356, 299-303.

(13) Liu, H.; Wang, B.; Fan, M.; Henson, N.; Zhang, Y.; Towler, B. F.; Harris, H. G. Study on carbon deposition associated with catalytic $\mathrm{CH} 4$ reforming by using density functional theory. Fuel 2013, 113, $712-718$.

(14) Qi, Q.; Wang, X.; Chen, L.; Li, B. Methane dissociation on $\operatorname{Pt}(111), \operatorname{Ir}(111)$ and $\operatorname{PtIr}(111)$ surface: A density functional theory study. Appl. Surf. Sci. 2013, 284, $784-791$.

(15) Gerceker, D.; Motagamwala, A. H.; Rivera-Dones, K. R.; Miller, J. B.; Huber, G. W.; Mavrikakis, M.; Dumesic, J. A. Methane Conversion to Ethylene and Aromatics on PtSn Catalysts. ACS Catal. 2017, 7, 2088-2100. 
(16) Liu, Z.-P.; Hu, P. General rules for predicting where a catalytic reaction should occur on metal surfaces: a density functional theory study of $\mathrm{C}-\mathrm{H}$ and $\mathrm{C}-\mathrm{O}$ bond breaking/making on flat, stepped, and kinked metal surfaces. J. Am. Chem. Soc. 2003, 125, 1958-1967.

(17) Prats, H.; Gutiérrez, R. A.; Piñero, J. J.; Viñes, F.; Bromley, S. T.; Ramírez, P. J.; Rodriguez, J. A.; Illas, F. Room Temperature Methane Capture and Activation by $\mathrm{Ni}$ Clusters Supported on $\mathrm{TiC}(001)$ : Effects of Metal-Carbide Interactions on the Cleavage of the $\mathrm{C}-\mathrm{H}$ Bond. J. Am. Chem. Soc. 2019, 141, 5303-5313, PMID: 30848129 .

(18) Trinchero, A.; Hellman, A.; Grönbeck, H. Methane oxidation over Pd and Pt studied by DFT and kinetic modeling. Surf. Sci. 2013, 616, $206-213$.

(19) Geng, C.; Weiske, T.; Li, J.; Shaik, S.; Schwarz, H. Intrinsic Reactivity of Diatomic 3d Transition-Metal Carbides in the Thermal Activation of Methane: Striking Electronic Structure Effects. J. Am. Chem. Soc. 2019, 141, 599-610.

(20) Sakbodin, M.; Wu, Y.; Oh, S. C.; Wachsman, E. D.; Liu, D. Hydrogen-Permeable Tubular Membrane Reactor: Promoting Conversion and Product Selectivity for Non-Oxidative Activation of Methane over an $\mathrm{Fe}\left(\mathrm{SiO}_{2}\right.$ Catalyst. Angew. Chem. Int. Ed. 2016, 55, 16149-16152.

(21) Impeng, S.; Khongpracha, P.; Sirijaraensre, J.; Jansang, B.; Ehara, M.; Limtrakul, J. Methane activation on Fe- and FeO-embedded graphene and boron nitride sheet: role of atomic defects in catalytic activities. $R S C A d v$. 2015, 5, 97918-97927.

(22) Su, Y.-Q.; Wang, Y.; Liu, J.-X.; Filot, I. A.; Alexopoulos, K.; Zhang, L.; Muravev, V.; Zijlstra, B.; Vlachos, D. G.; Hensen, E. J. Theoretical Approach To
Predict the Stability of Supported SingleAtom Catalysts. ACS Catal. 2019, 9, 3289-3297.

(23) Wu, S.-Y.; Lin, C.-H.; Ho, J.-J. Densityfunctional calculations of the conversion of methane to methanol on platinumdecorated sheets of graphene oxide. Phys. Chem. Chem. Phys. 2015, 17, 2619126197.

(24) Cui, X.; Li, H.; Wang, Y.; Hu, Y.; Hua, L.; Li, H.; Han, X.; Liu, Q.; Yang, F.; He, L.; Chen, X.; Li, Q.; Xiao, J.; Deng, D.; Bao, X. Room-Temperature Methane Conversion by Graphene-Confined Single Iron Atoms. Chem 2018, 4, $1902-1910$.

(25) Guo, X. et al. Direct, Nonoxidative Conversion of Methane to Ethylene, Aromatics, and Hydrogen. Science 2014, 344 , 616-619.

(26) Li, H.-F.; Jiang, L.-X.; Zhao, Y.-X.; Liu, Q.-Y.; Zhang, T.; He, S.-G. Formation of Acetylene in the Reaction of Methane with Iron Carbide Cluster Anions $\mathrm{FeC}_{3}^{-}$under High-Temperature Conditions. Angew. Chem. Int. Ed. 2018, 57, 2662-2666.

(27) Kresse, G.; Hafner, J. Ab initio molecular dynamics for liquid metals. Phys. Rev. B 1993, 47, 558-561.

(28) Kresse, G.; Hafner, J. Ab initio moleculardynamics simulation of the liquid-metalamorphous-semiconductor transition in germanium. Phys. Rev. $B$ 1994, 49, 14251-14269.

(29) Kresse, G.; Furthmüller, J. Efficiency of ab-initio total energy calculations for metals and semiconductors using a plane-wave basis set. Comput. Mater. Sci. 1996, 6, 15 -50 .

(30) Kresse, G.; Furthmüller, J. Efficient iterative schemes for ab initio total-energy calculations using a plane-wave basis set. Phys. Rev. B 1996, 54, 11169-11186. 
(31) Perdew, J. P.; Burke, K.; Ernzerhof, M. Generalized Gradient Approximation Made Simple. Phys. Rev. Lett. 1996, 77, 3865-3868.

(32) Blöchl, P. E. Projector augmented-wave method. Phys. Rev. B 1994, 50, 1795317979 .

(33) Kresse, G.; Joubert, D. From ultrasoft pseudopotentials to the projector augmented-wave method. Phys. Rev. B 1999, 59, 1758-1775.

(34) Press, W. H.; Teukolsky, S. A.; Vetterling, W. T.; Flannery, B. P. Numerical Recipes in $C$ (2Nd Ed.): The Art of Scientific Computing; Cambridge University Press: New York, NY, USA, 1992.

(35) Henkelman, G.; Uberuaga, B. P.; Jónsson, H. A climbing image nudged elastic band method for finding saddle points and minimum energy paths. J. Chem. Phys. 2000, 113, 9901-9904.

(36) Henkelman, G.; Jónsson, H. Improved tangent estimate in the nudged elastic band method for finding minimum energy paths and saddle points. J. Chem. Phys. 2000, 113, 9978-9985.

(37) Henkelman, G.; Jónsson, H. A dimer method for finding saddle points on high dimensional potential surfaces using only first derivatives. J. Chem. Phys. 1999, 111, 7010-7022.

(38) Pulay, P. Convergence acceleration of iterative sequences. the case of scf iteration. Chem. Phys. Lett. 1980, 73, 393 - 398.

(39) VTSTTools 3.1, Henkelman group, University of Texas, Austin, TX, USA. https://theory.cm.utexas.edu/ vtsttools/, Accessed: 2019-07-12.

(40) Momma, K.; Izumi, F. VESTA3 for threedimensional visualization of crystal, volumetric and morphology data. J. Appl. Crystallogr. 2011, 44, 1272-1276.
(41) P.J. Linstrom and W.G. Mallard, Eds., NIST Chemistry WebBook, NIST Standard Reference Database Number 69, National Institute of Standards and Technology, Gaithersburg MD, 20899. https: //doi.org/10.18434/T4D303, Accessed: 2019-11-15.

(42) Jansen, A. P. J. Introduction to kinetic Monte Carlo simulations of surface reactions, Lecture Notes in Physics 856; Springer: Heidelberg, 2012.

(43) MATLAB, 8.0.0.783; The MathWorks Inc.: Natick, Massachusetts.

(44) Moiraghi, R.; Lozano, A.; Busnengo, H. F. Theoretical Study of the Dissociative Adsorption of Methane on $\operatorname{Ir}(111)$ : The Role of Steps and Surface Distortions at High Temperatures. J. Phys. Chem. C 2016, 120, 3946-3954.

(45) Schultz, R. H.; Armentrout, P. B. Gasphase metal ion ligation: collision-induced dissociation of aquairon $\left(\mathrm{Fe}\left(\mathrm{H}_{2} \mathrm{O}\right)_{x}^{+}\right)$and iron-methane $\left(\mathrm{Fe}\left(\mathrm{CH}_{4}\right)_{x}^{+}\right) \quad(\mathrm{x}=1-4) . \quad J$. Phys. Chem. 1993, 97, 596-603.

(46) Wu, C.; Gates, I. D. Methane activation by a single iron atom supported on graphene: Impact of substrates. Mol. Catal. 2019, 469, $40-47$.

(47) Tsuji, Y.; Yoshizawa, K. Adsorption and Activation of Methane on the (110) Surface of Rutile-type Metal Dioxides. $J$. Phys. Chem. C 2018, 122, 15359-15381.

(48) Juurlink, L. B. F.; McCabe, P. R.; Smith, R. R.; DiCologero, C. L.; Utz, A. L. Eigenstate-Resolved Studies of Gas-Surface Reactivity: $\mathrm{CH}_{4}\left(\nu_{3}\right)$ Dissociation on $\mathrm{Ni}(100)$. Phys. Rev. Lett. 1999, 83, 868-871.

(49) Brass, S. G.; Ehrlich, G. Dissociative and molecular adsorption of methane on rhodium. Surf. Sci. 1987, 187, 21-35. 